\title{
Enhanced ACh Sensitivity Is Accompanied by Changes in ACh Receptor Channel Properties and Segregation of ACh Receptor Subtypes on Sympathetic Neurons during Innervation in vivo
}

\author{
Brenda L. Moss ${ }^{\mathrm{a}}$ and Lorna W. Role \\ Department of Anatomy and Cell Biology, Center for Neurobiology and Behavior, Columbia University College of \\ Physicians and Surgeons, New York, New York 10032
}

Although presynaptic input can influence the number and distribution of ACh receptors (AChRs) on muscle, the role of cellular interactions in the development of transmitter sensitivity in neurons is less clear. To determine whether presynaptic input modifies neuronal AChR channel function and distribution, we must first ascertain the profile of changes in receptor properties relative to the timing of synapse formation. We have examined the temporal aspects of synaptogenesis in the lumbar sympathetic ganglia of the embryonic chick in anatomical experiments with anterograde 1,1'-dioctadecyl-3,3,3',3'-tetramethylindocarbocyanine perchlorate labeling of presynaptic inputs and cytochrome oxidase histochemistry. Biophysical studies of sympathetic neurons, within hours of removal from animals at different stages relative to synapse formation, show that both the properties and distribution of AChR channels are modified concurrent with a significant increase in presynaptic input to the neurons. The most striking change in AChR channel distribution is revealed by patching multiple sites on the surface of individual neurons. Following innervation in vivo, many neurons express only one of the four AChR channel subtypes and the AChRs are clustered in discrete, highactivity patches. Furthermore, when neurons at this stage express more than one AChR channel subtype, the different classes are often spatially segregated from one another on the cell surface. This contrasts with patches from neurons removed earlier on, which have lower overall activity, often comprised of multiple channel subtypes. Comparison of the AChR properties of acutely dispersed neurons to those of neurons maintained in vitro indicates that most features of AChR channels are conserved despite their removal from presynaptic and other in vivo influences. These findings are consistent with inductive interactions between pre- and postsynaptic neurons playing an important regulatory role in transmitter receptor expression.

Received Nov. 22, 1991; revised June 19, 1992; accepted June 29, 1992.

We thank Dr. A. J. Silverman, Dr. J. Dodd, and A. Dolorico for help with the Dil experiments, Dr. G. M. Mawe for participating in initial cytochrome oxidase experiments, and Dr. R. Loring for his generous gift of neuronal bungarotoxin. We also thank Drs. L. Chasin, S. DeRiemer, D. Kelley, and S. Siegelbaum for their critical reading of an earlier version of the manuscript. This work was supported by NIH Award NS22061 (L.W.R.).

Correspondence should be addressed to Lorna W. Role, Department of Anatomy and Cell Biology, Center for Neurobiology and Behavior, 630 West 168 Street, Room 12-404, Columbia University P and S, New York, NY 10032.

aPresent address: Department of Neurobiology and Behavior, State University of New York at Stony Brook, Stony Brook, NY 11794.

Copyright (C) 1993 Society for Neuroscience 0270-6474/93/130013-16\$05.00/0
[Key words: sympathetic neurons, Dil, cytochrome oxidase, ACh sensitivity, ACh receptor, neuronal bungarotoxin]

The expression of transmitter sensitivity is fundamental to synaptogenesis. Studies of the formation of the neuromuscular synapse have shown that the incoming motor nerve plays an important role in the development of postsynaptic transmitter sensitivity. Innervation of embryonic skeletal muscle induces an increase in ACh sensitivity at the site of nerve-muscle contact by regulating $A C h$ receptor ( $A C h R$ ) number and distribution (reviewed in Schuetze and Role, 1987). The postsynaptic response is further modified by subsequent changes in the functional properties of the AChR channels: the single-channel conductance increases and the apparent mean open time decreases (reviewed in Schuetze and Role, 1987; Brehm and Henderson, 1988).

Presynaptic input can also influence the distribution and functional properties of AChRs in neurons. To date, most studies evaluating the role of presynaptic input in the regulation of neuronal AChRs have examined mature neurons, rather than studying AChR expression during synaptogenesis. Studies of mature neurons, employing toxin binding (Marshall, 1981; Loring and Zigmond 1987) or monoclonal antibodies to receptor subunits (Jacob et al., 1984; Sargent and Pang, 1989; Jacob, 1991) to reveal the distribution of AChRs, indicate that the AChRs are clustered at the synapses. Furthermore, studies of the denervation and subsequent cross-reinnervation of mature sympathetic neurons in frog indicate that the incoming nerve influences AChR channel kinetics (Marshall, 1985). However, denervation of mature neurons apparently does not alter the number or distribution of AChRs as initially suggested (Kuffler et al., 1971; Dunn and Marshall, 1985; Jacob and Berg, 1988; but see Sargent and Pang, 1988).

There is relatively little known about the initial development and subsequent changes in AChRs during synapse formation on neurons. Recent work on chick ciliary ganglion in vivo by Jacob (1991) shows a tight temporal relationship between the appearance of synapses and the expression of surface AChRs detected by monoclonal antibody 35 . In addition, recent studies of central neurons indicate upregulation of receptor subunit mRNA concurrent with the expression of presynaptic ChAT in the chicken lateral spiriform nucleus in vivo (Daubas et al., 1990).

Several studies have examined the development of ACh sensitivity of neurons maintained in vitro in the presence or absence of presynaptic input (Role, 1988; Gardette et al., 1991; Hume 
and Honig, 1991). These studies indicate that presynaptic input enhances the ACh sensitivity of postsynaptic neurons fairly rapidly. The upregulation of the ACh sensitivity of neurons by the incoming nerve is mimicked by a soluble factor(s) derived from presynaptic neurons and is apparently due to an increase in the rate of appearance of new AChRs on the cell surface (Role, 1988; Gardette et al., 1991). A limitation of these studies, however, is that they assess changes in ACh sensitivity relative to the onset of innervation in vitro. These changes may be superimposed on perturbations in neuronal function that take place due to removal of the neurons from other regulatory influences to which they are subject in vivo.

Our first goal was to examine whether innervation of chicken lumbar sympathetic neurons in vivo alters their ACh sensitivity. Previous electron microscopic data had indicated that by $1 \mathrm{~d}$ posthatch, approximately $25 \%$ of the adult number of synaptic profiles are present (Hruschak et al., 1982). To identify when presynaptic fibers project to the lumbar sympathetic ganglia during embryogenesis, we injected $1,1^{\prime}$-dioctadecyl-3,3,3',3'-tetramethylindocarbocyanine perchlorate (Dil) into the preganglionic nucleus to label presynaptic input orthogradely. To evaluate whether the arrival of presynaptic fibers was associated with functional innervation of the neurons, we assessed their electrical activity by cytochrome oxidase (CO) histochemistry (Mawe et al., 1990). Both techniques indicate a significant increase in innervation of lumbar ganglia between embryonic day (ED) 11 and ED 17. To assess changes in ACh sensitivity during innervation in vivo, we recorded from neurons immediately after dispersal (without enzymc trcatmcnt) and compared pcak AChevoked macroscopic currents at each embryonic age. These studies reveal a 4.4-fold increase in ACh sensitivity during innervation in vivo.

Neuronal AChRs, like muscle AChRs, may be further modified by changes in their functional properties during the development of presynaptic input. Previous studies have shown that neurons removed at different developmental stages and maintained in vitro express AChR channels with distinct biophysical characteristics (Moss et al., 1989). These studies do not resolve, however, whether these changes in AChR channels might be related to innervation or whether the biophysical properties of AChR channels are faithfully retained by neurons removed from their in vivo setting and maintained in vitro. Our next goal was to determine whether changes in the distribution and functional behavior of $\mathrm{ACh}$-activated channels take place during innervation in vivo. We find that the observed increase in $\mathrm{ACh}$ sensitivity in acutely dispersed neurons may be due, in part, to changes in AChR channel properties. Comparison of ACh-activated single-channel currents in neurons acutely dispersed on ED 11 to those in neurons isolated on ED 17 revealed multiple AChR subtypes and changes in the properties of these channels that are consistent with the net increase in $\mathrm{ACh}$-induced conductance. In addition, analysis of the neuronal bungarotoxin (NBT) sensitivity of the AChRs revealed differences that further distinguish the AChR subtypes from one another.

The most striking change in AChR channels following innervation was revealed by experiments where the AChR channel distribution of individual neurons was "mapped" by recording AChR channel activity at multiple sites over the cell surface. Regions of high channel activity (or "hot spots") are found on a majority of the neurons at later stages, indicating clustering of functional AChR channels. Furthermore, the different AChR channel subtypes are apparently segregated both on a cell-bycell basis, as well as spatially segregated from one another on the surface of individual cells. If these hot spots of AChR channel subtypes reflect individual synaptic sites, this organization of AChR subtypes might encode critical differences in the efficacy of transmission at distinct inputs.

\section{Materials and Methods}

DiI labeling. For anterograde labeling of the projections from preganglionic neurons to sympathetic ganglia, the spinal cord and sympathetic chains were dissected out as a single block of tissue from both ED 11 and ED 17 chickens. The chest cavity was opened from the ventral surface, and transverse cuts were made at the cervical and sacral levels. Two longitudinal cuts were then made lateral to each chain. The tissue was removed and fixed for $1 \mathrm{hr}$ in $4 \%$ paraformaldchyde in $0.1 \mathrm{M}$ sodium phosphate buffer ( $\mathrm{pH} 7.3$, room temperature). The tissue was then rinsed in three changes of $0.1 \mathrm{M}$ phosphate buffer and stored at $4^{\circ} \mathrm{C}$ in buffer with $10 \mu \mathrm{M}$ azide.

In avians, the preganglionic neurons innervating the lumbar sympathetic chain ganglia are located in the dorsal (rather than intermediolateral) spinal cord (Levi-Montalcini, 1950; Yip, 1986, 1990). To inject DiI into the preganglionic nucleus, a longitudinal cut was made along the dorsal surface of the vertebral column exposing the spinal cord. To increase the efficiency of Dil labeling, a micropipette (tip diameter approximately $10 \mu \mathrm{m}$ ) was first used to perforate the dorsal surface of the spinal cord. A second micropipette filled with DiI (Molecular Probes) dissolved in Triton X-100 was used to inject the DiI solution into the spinal cord (cervical to sacral) dorsal and lateral to the lution into the spinal cord (cervical to sacral) dorsal and lateral to the central canal (schematic Fig. 1A). To prevent nonspecific labeling due to dispersion of DiI in the buffer, the injected area was repeatedly blotted with filter paper. Fuorescence micrographs of an ED 11 spinal cord, which was embedded and vibratome sectioned (see below) immediately following Dil injection, indicated that the region of the preganglionic nucleus was completely labeled (Fig. $I B$ ). For anterograde diffusion of the DiI, the tissue was stored in $0.1 \mathrm{M}$ phosphate buffer with azide in the dark at $37^{\circ} \mathrm{C}$ for $4-8$ weeks following injection.

DiI-labeled lumbar sympathetic chains (L1-L5) were dissected from the fixed tissue block, incubated at $37^{\circ} \mathrm{C}$ in $6 \%$ gelatin for $10 \mathrm{~min}$ and $12 \%$ gelatin for $5 \mathrm{~min}$, and embedded in egg yolk:gelatin (12\%) at $1: 1$. Egg-gel blocks were stored in $4 \%$ paraformaldehyde (in $0.1 \mathrm{~m}$ sodium phosphate buffer) for $2-3 \mathrm{~d}$ in the dark at $4^{\circ} \mathrm{C}$ until sufficiently firm for sectioning. Vibratome sections (20-30 $\mu \mathrm{m}$ thick, 15-25 serial longitudinal sections per chain) were cut and mounted onto gelatin-subbed slides with $\mathrm{Gel} / \mathrm{Mount}$ (Biomeda). To visualize neuronal cell bodies, sections adjacent to those examined for Dil labeling were stained with cresyl violet. Sections were viewed with an epifluorescence microscope equipped with a rhodamine filter set. Photographs were taken with a $40 \times$ Plan Neofluar objective on Ilford HP5 (800 ASA) black-and-white film.

Cytochrome oxidase (CO) histochemistry. Lumbar sympathetic chains were dissected from ED 11 and ED 18 chickens, fixed in 4\% paraformaldehyde (in $0.1 \mathrm{~m}$ phosphate buffer, $\mathrm{pH} 7.3$ ) for $1 \mathrm{hr}$ at room temperature, rinsed in phosphate buffer, and immersed in $30 \%$ sucrose in $0.1 \mathrm{M}$ phosphate buffer overnight. The tissue was frozen in OCT compound (TissueTek), and 10-15 $\mu \mathrm{m}$ cryostat sections were collected onto gelatin-subbed slides.

Sections from ED 11 and ED 18 animals were processed concurrently for $\mathrm{CO}$ histochemistry. The sections were first rinsed in $0.1 \mathrm{M}$ Tris $\mathrm{HCl}$ (pH 7.4) for 5 min. To intensify the diaminobenzidine (DAB) reaction, sections were preincubated in $2 \% \mathrm{CoCl}_{2}$ (in $0.1 \mathrm{M}$ Tris $\mathrm{HCl}$ ) for $5 \mathrm{~min}$. The sections were then rinsed for $15 \mathrm{~min}$ in Tris $\mathrm{HCl}$ buffer, followed by a $5 \mathrm{~min}$ rinse in $0.1 \mathrm{M}$ sodium phosphate buffer. CO activity was assayed by incubating the sections in a solution of cytochrome $C(0.3$ $\mathrm{mg} / \mathrm{ml}$; type III, Sigma) and DAB $(0.5 \mathrm{mg} / \mathrm{ml})$ in $0.1 \mathrm{M}$ sodium phosphate buffer at $37^{\circ} \mathrm{C}$ until reaction product was apparent (approximately $30-60 \mathrm{~min}$ ). The reaction was stopped by rinsing in phosphate buffer and the sections were dehydrated in ethanol, cleared in xylene, and coverslipped with Permount.

We quantified the density of $\mathrm{CO}$ reaction product using computerassisted video-microdensitometry with software obtained from Imaging Research, Toronto, Canada (see Mawe et al., 1990). Briefly, bright-field images of sections were captured and displayed on the video system, and the perimeters of individual neurons randomly selected from all lumbar ganglia (L1-L5) were traced with a cursor. The optical density (OD) of the circumscribed area directly correlates with the density of 
reaction product and hence the level of $\mathrm{CO}$ activity in the individual cell (Mawe et al., 1990).

Preparation of acutely dispersed neurons for electrophysiological recording. All electrophysiological recording [with the exception of neuronal bungarotoxin (NBT) experiments; see below] was done on acutely dispersed sympathetic neurons. Briefly, lumbar sympathetic chains from ED 11 and ED 17 chickens were dissected directly into Dulbecco's modified Eagle's medium (GIBCO) supplemented with horse serum $(10 \%)$, penicillin $(50 \mathrm{U} / \mathrm{ml})$, streptomycin $(50 \mu \mathrm{g} / \mathrm{ml})$, glutamine $(2 \mathrm{~mm})$, nerve growth factor (NGF; $2.5 \mathrm{~S}, 0.01 \mu \mathrm{g} / \mathrm{ml}$; kindly provided by $\mathrm{P}$. Osbourne and G. Johnson, Washington University, St. Louis, MO), and ED 11 chick embryo extract $(5 \%, v / v)$. After removing as much of the connective tissue sheath as possible, the ganglia were dispersed to single cells by repeated passage through a fire-polished Pasteur pipette. The cells were then plated at one chain per $35 \mathrm{~mm}$ dish on a $0.1 \%$ poly-(Lornithine) substrate. Neurons dispersed in this manner were well isolated, phase bright, and spherical with no or few processes. Cells were used for physiological recording 1-2 hr after plating.

Macroscopic current recording. For macroscopic current recording, we used the whole-cell tight-seal configuration of the patch-clamp technique (Hamill et al., 1981). In each experiment, the plating medium was removed and the neurons were gently rinsed with three changes of L-15 tissue culture medium (GIBCO) supplemented with $4.5 \mathrm{~mm}$ calcium. The culture dish was placed on the stage of a Zeiss inverted microscope equipped with phase-contrast optics. Cells were viewed at $400 \times$ with a $40 \times$ objective. All experiments were done at room temperature $\left(22-24^{\circ} \mathrm{C}\right)$.

Patch pipettes were pulled from Omega Dot tubing (Glass Co. of America, Bargaintown, NJ) on a Kopf vertical puller and coated with Sigmacote (Sigma) to reduce capacitance. The recording pipette was connected to a Dagan 8900 patch-clamp amplifier. Pipette resistances were 8-12 M $\Omega$.

The recording pipette was filled with an intracellular solution consisting of $140 \mathrm{~mm} \mathrm{KCl}, 2 \mathrm{~mm} \mathrm{MgCl}, 11 \mathrm{~mm}$ EGTA, $1 \mathrm{~mm} \mathrm{CaCl}$, and $5 \mathrm{~mm} \mathrm{Mg}$-ATP buffered to pH 7.2 with $10 \mathrm{~mm}$ HEPES. The pressure ejection pipette used to apply ACh contained ACh $(500 \mu \mathrm{M})$ dissolved in an extracellular solution consisting of $150 \mathrm{~mm} \mathrm{NaCl}, 3 \mathrm{~mm} \mathrm{KCl}, 1$ $\mathrm{mM} \mathrm{MgCl}_{2}, 1 \mathrm{mM} \mathrm{CaCl}_{2}$, and $10 \mathrm{~mm}$ HEPES titrated to $\mathrm{pH} 7.2$ with 1 M NaOH.

For each cell, rest potential was measured as soon as the whole-cell configuration was achieved. Only cells with rest potentials more negative than $-40 \mathrm{mV}$ were used; these cells were then voltage clamped at -60 $\mathrm{mV}$. ACh at $500 \mu \mathrm{M}$ was pressure-applied (approximately $8 \mathrm{psi}$ ) for 10 sec from a pipette placed approximately $50 \mu \mathrm{m}$ from the soma. Previous experiments have demonstrated that agents applied in this manner are diluted by $<10 \%$ (Choi and Fischbach, 1981). The peak amplitudes of ACh-evoked currents were determined from the average of 5-10 points at the peak of the digitized currents recorded with $4 \mathrm{kHz}$ filtering.

Single-channel recording. Single-channel recording was done using conventional cell-attached and inside-out patch-clamp techniques (Hamill et al., 1981). Detailed methods for cell-attached patch recording and single-channel analysis have been described previously (Moss et al., 1989). For inside-out patch recording, the plating medium was replaced with an intracellular solution consisting of $140 \mathrm{~mm} \mathrm{CsCl}, 1$ mм CaCl, 5 mм Mg-ATP, 11 mм EGTA, and 10 mм HEPES titrated to $\mathrm{pH} 7.3$ with $\mathrm{KOH}$. The recording pipette contained $\mathrm{ACh}$ dissolved in an extracellular solution (see above). After the membrane patch was excised, channel openings were routinely examined for distortion indicative of vesicle formation. In such cases, it was sometimes possible to disrupt the vesicle by passing the pipette tip through the solutionair interface.

Identification of channel amplitude classes. Channel openings in cellattached patches were assigned to the $\mathbf{S}, \mathbf{M}$, or $\mathbf{L}$ (or $\mathbf{S}_{17}, \mathbf{M}_{17}, \mathbf{L}_{17}$, or $\mathrm{XL}$ ) channel classes based on their current amplitude at a patch potential of $-50 \mathrm{mV}$ relative to rest potential. As shown in Figures $7 C$ and $9 C$, the channel classes are well separated at this hyperpolarized potential. For each embryonic age, amplitude histograms from patches containing all channel classes were used to determine the mean amplitude and range for each class. In patches containing a subset of the channel classes, an opening was assigned to a given class if its current amplitude fell within one standard deviation for that class. Events that could not be classified according to these criteria were considered ambiguous and were ignored.

AChR block by NBT. Experiments examining AChR block by NBT were done using neurons that had been maintained in vitro. Lumbar chain ganglia were dissected from ED 11 chickens, dispersed to indi-
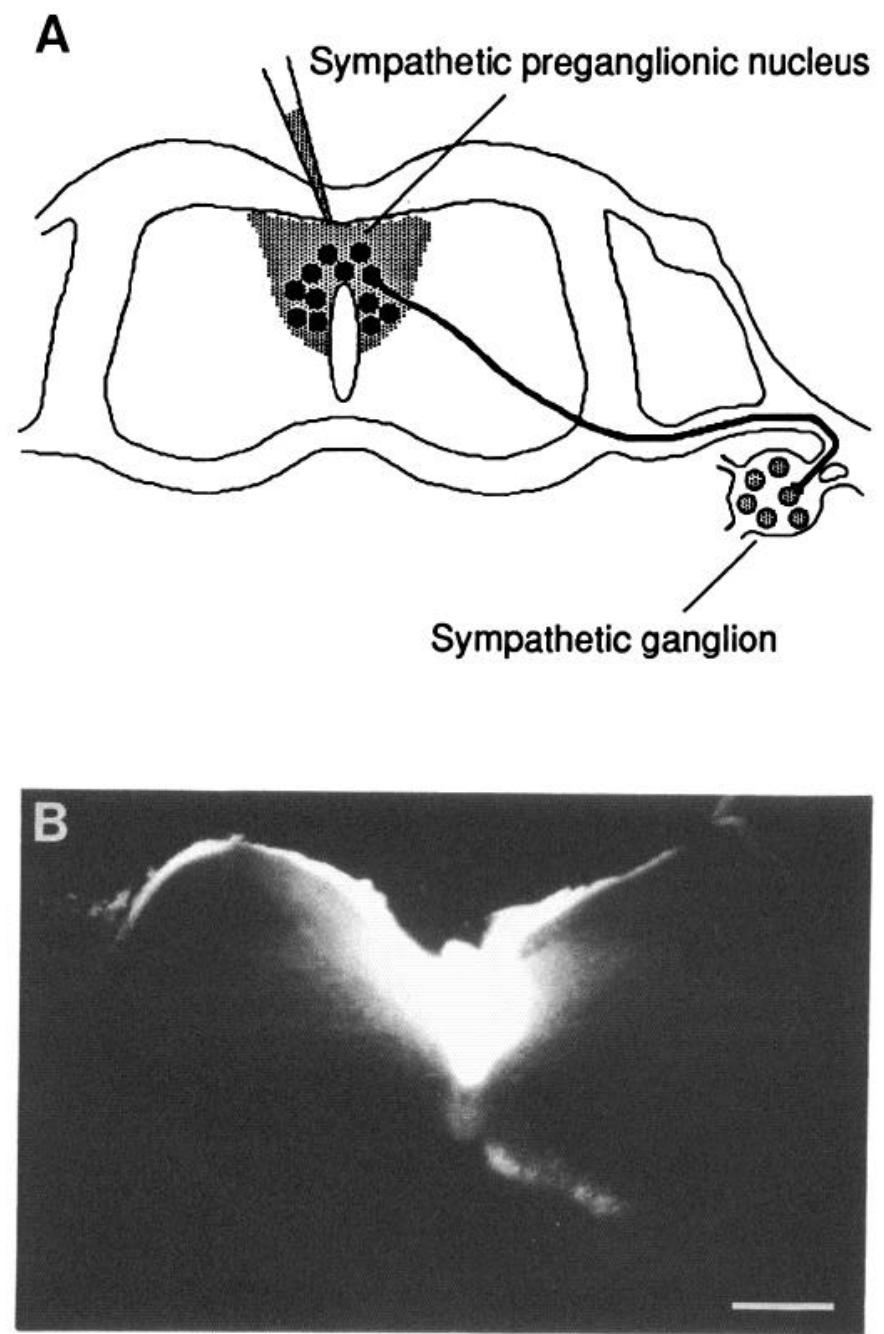

Figure 1. DiI injected into the dorsal spinal cord labels the region of the sympathetic preganglionic nucleus. $A$, Schematic diagram of a cross section through the spinal cord and sympathetic chain illustrating microelectrode injection of DiI (shaded area) into the preganglionic nucleus. $B$, Fluorescence micrograph of an ED 11 spinal cord that was embedded and vibratome sectioned immediately following DiI injection. The section is oriented as in the schematic diagram above. The region of the preganglionic nucleus has been completely labeled. Scale bar, $200 \mu \mathrm{m}$.

vidual cells, and plated under conditions that suppress proliferation of non-neuronal cells as previously described in detail (Role, 1984). Cultures were used for physiological recording 4-10 d after plating.

Each NBT experiment was performed using the cell-attached patch configuration according to the following protocol. The initial level of AChR channel activity was determined from three to five patches on neurons bathed in L-15 tissue culture medium. The cells were then incubated in NBT (15-100 nM in L-15; provided by Dr. Ralph Loring, Northeastern University, Boston, MA) for $30-45 \mathrm{~min}$ at room temperature. Channel activity was then determined from three to five patches on neurons incubated with NBT and with NBT included in the ACh solution. Recovery was determined from three to five additional patches after the neurons were rinsed three times with L-15 (30-60 min).

For each patch, we recorded for $5 \mathrm{~min}$ at a patch potential of -50 $\mathrm{mV}$ relative to rest potential $(\mathrm{ACh}=2.5 \mu \mathrm{M})$. We then scored every patch recording for the presence of each channel class. A patch was considered an "active patch" for a given class if one or more openings belonging to that amplitude class were observed.

Distribution of surface AChRs. To map the cell surface distribution of the S, M, L, and XL channel classes, three to five cell-attached patches were obtained on individual neurons. The patch pipette was positioned at approximately 3-5 $\mu \mathrm{m}$ intervals around the perimeter of the soma 

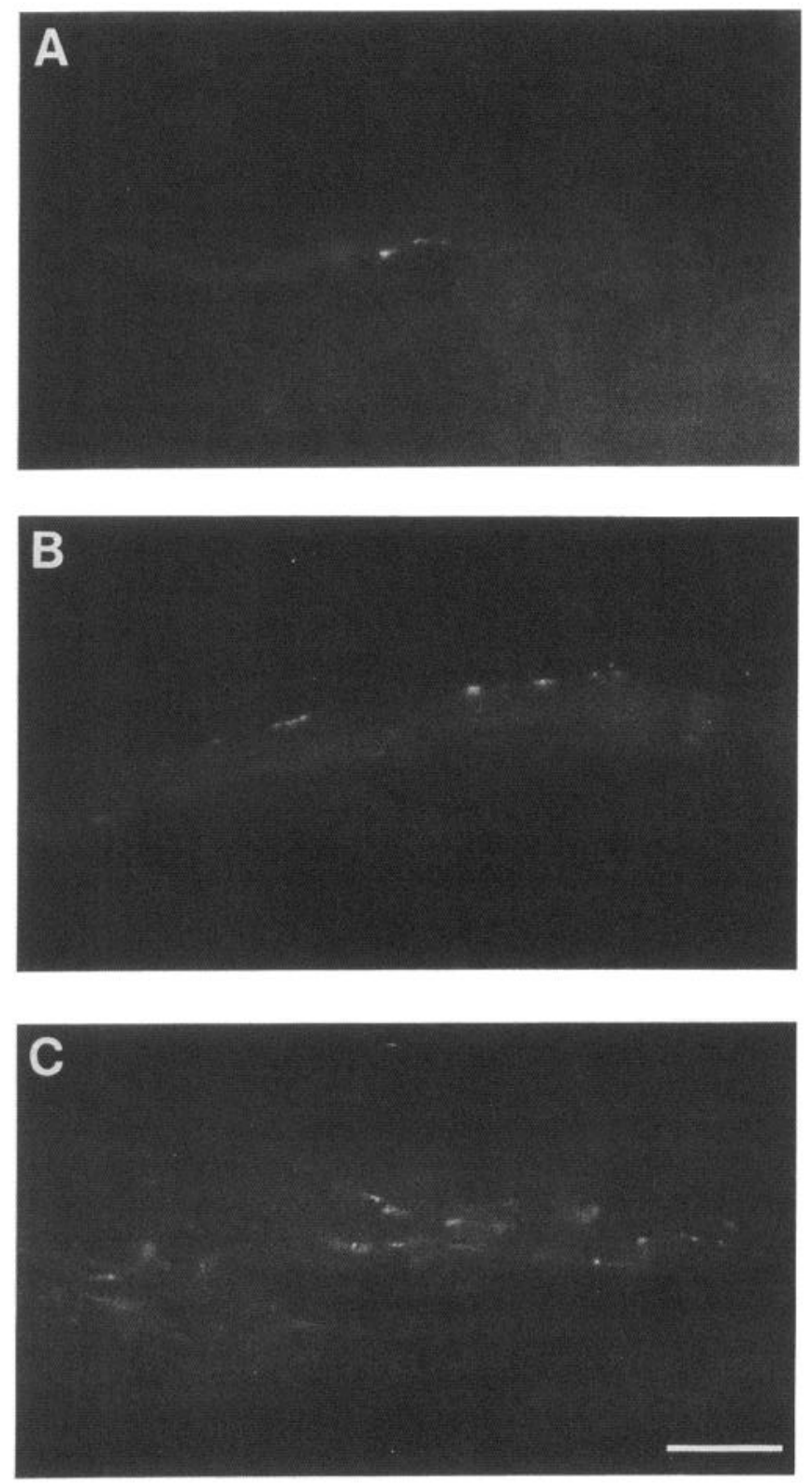

Figure 2. Few Dil-labeled preganglionic fibers are observed in ED 11 lumbar sympathetic ganglia: fluorescence micrographs of vibratomesectioned lumbar sympathetic ganglia from an embryo fixed and $\mathrm{Di}$ injected on ED 11 showing the most intensely labeled fibers observed. $A$, Single labeled fiber among ganglion cell bodies that were visualized by staining adjacent sections with cresyl violet. Such staining indicated approximately $20-25$ cell bodies in the field shown here (data not shown). $B$ and $C$, Labeled fibers within ganglionic connectives. Scale bar, 20 $\mu \mathrm{m}$.

$(\approx 10-20 \mu \mathrm{m}$ in diameter). If the quality of the recording was compromised (i.e., cell swelling, blebbing, or apparent membrane breakdown), mapping was discontinued. We recorded from each patch for $3 \mathrm{~min}$ at a patch potential of $-50 \mathrm{mV}$ relative to rest potential $(2.5 \mu \mathrm{M} \mathrm{ACh})$. We then scored all patch recordings for the presence of each channel class and determined the overall opening frequency (number of openings/sec, all classes combined).

Neuronal membrane surface area. In most experiments, surface area was calculated using the formula for the surface area of a sphere, $A=$ $\pi d^{2}(A=$ surface area and $d=$ diameter). Cell diameter was measured with a calibrated reticle at $500 \times$. To check the accuracy of this method, in some cases we also calculated surface area from measurements of cell capacitance. The spherical shape of the cells enabled us to estimate cell capacitance using the capacitance compensation circuit of the patchclamp amplifier (List EPC-7). In the cell-attached patch configuration, a $5 \mathrm{msec}, 10 \mathrm{mV}$ hyperpolarizing pulse was applied and the fast capacitative transients (due primarily to pipette capacitance) were canceled with the capacitance circuit. The patch was then disrupted and the cell was voltage clamped at rest potential (only cells with rest potentials more negative than $-40 \mathrm{mV}$ were used). Series resistance ranged from 5 to $10 \mathrm{M} \Omega$. The increase in capacitance after breaking the patch, due to the additional cell capacitance, was estimated by noting the level of capacitance required for subsequent cancellation. Cell surface area was then calculated by dividing cell capacitance by specific membrane capacitance $\left(\approx 1 \mu \mathrm{F} / \mathrm{cm}^{2}\right)$. We found that, for each embryonic age, the relationship between the surface area determinations based on the two approaches was linear; a plot of surface area from cell diameter versus surface area from cell capacitance yielded a straight line with a slope of approximately 0.5 (ED 11: $r=0.83, n=24$; ED 17: $r=0.77, n=20$ ).

\section{Results}

The number of preganglionic fibers and bouton-like structures in lumbar chain ganglia increases between ED 11 and ED 17

To determine the time of arrival of preganglionic fibers to lumbar sympathetic ganglia, we labeled the region of the preganglionic cell bodies with DiI and examined the ganglia for orthograde labeling of incoming fibers (see Materials and Methods, Fig. 1). Examination of ganglia and the interganglionic connectives from four ED 11 embryos (eight sympathetic chains) revealed very few labeled neurites. In serial sections of four chains ( 56 sections) from two DiI-injected embryos, labeled fibers were found in only seven sections from one embryo (Fig. 2). Most DiI-labeled neurites were within fiber tracts (Fig. $2 B, C$ ). Only one DiI-labeled process was observed among cell bodies of the ganglionic neurons (Fig. $2 A$ ), which were visualized by staining adjacent sections with cresyl violet (data not shown). These results indicate that there is little preganglionic input to lumbar sympathetic ganglion neurons by ED 11 .

In contrast, injection of DiI into the sympathetic preganglionic nucleus of ED 17 embryos labeled many fibers and boutonlike structures within the lumbar sympathetic chain. Examination of serial sections of three chains ( 73 sections) from ED 17 embryos revealed both labeled fibers and bouton-like structures in all sections (Fig. 3). In contrast to ED 11, many labeled processes were found among ganglion cell bodies (Fig. 3A,B), as well as within fiber tracts (Fig. $3 C$ ). Most Dil-labeled fibers were studded with a series of discrete, bouton-like swellings and often appeared to envelope cell bodies of neurons in more rostral ganglia (Fig. $3 D-F$ ). In some cases, examination of such sections at different planes of focus revealed labeled axons leading to these bouton-like swellings (data not shown). It should be noted that these results indicate a relative increase in the level of innervation between ED 11 and ED 17, rather than the absolute degree of innervation at either embryonic age. Because of the thickness of the sections (approximately two to three cells thick), only the most brightly labeled cells are readily visible.

\section{Synaptic activity, measured by $\mathrm{CO}$ histochemistry, increases with the arrival of preganglionic inputs}

Since preganglionic fibers and bouton-like structures can be visualized within lumbar sympathetic ganglia by ED 17, we examined whether there was a concurrent increase in synaptic input to ganglionic neurons. Electrophysiological recording from embryonic ganglia, however, is both technically difficult and restricted to neurons close to the surface of the ganglia (Dryer and Chiappinelli, 1985). To determine the innervation status of a large population of neurons, we assayed $\mathrm{CO}$ activity of 

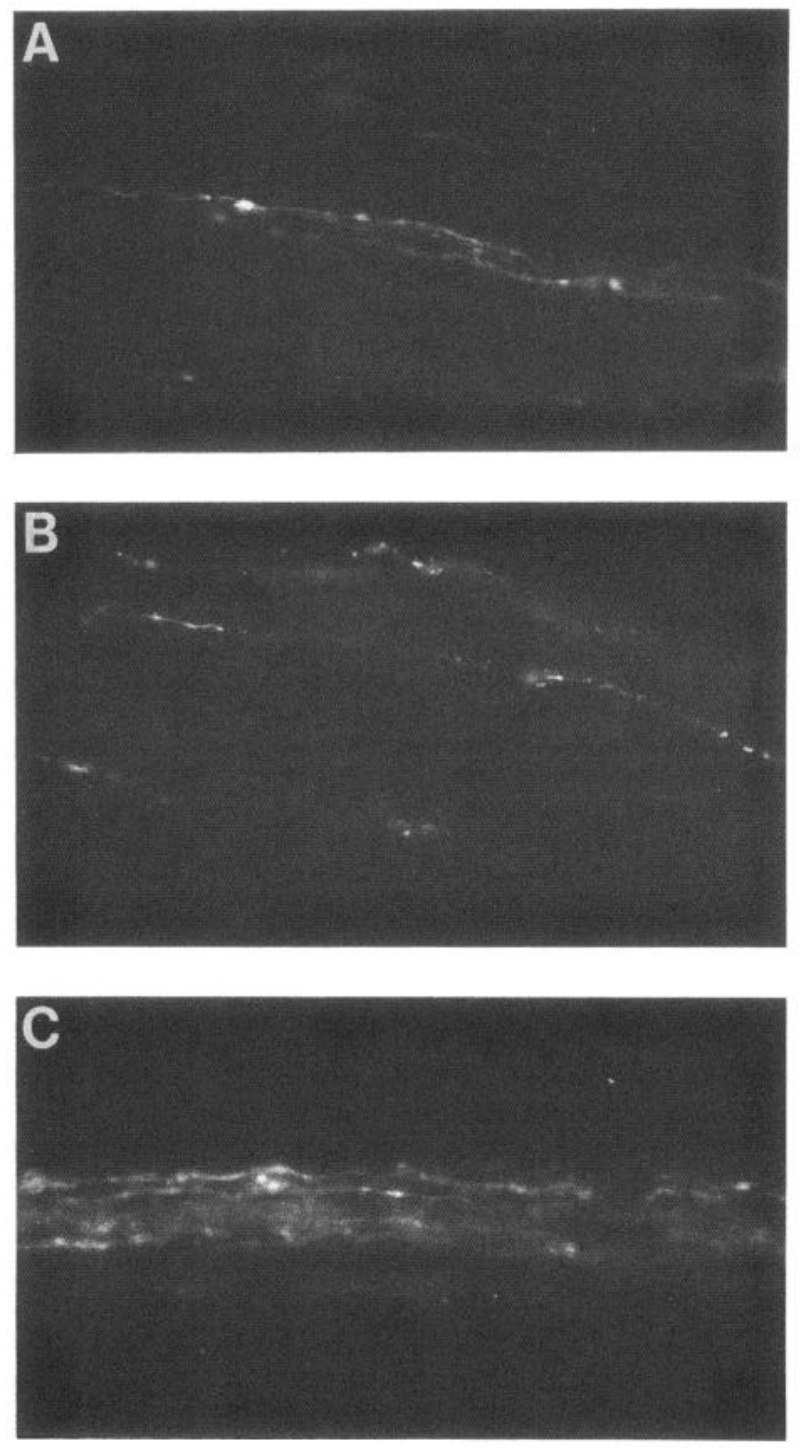

Figure 3. The number of DiI-labeled fibers and bouton-like structures is increased substantially by ED 17: fluorescence micrographs of a vibratomesectioned lumbar sympathetic chain from an embryo fixed and injected with DiI on ED 17. $A$ and $B$, Labeled fibers among ganglion cell bodies. Cresyl violet staining of adjacent sections indicated approximately 20-25 neuronal cell somas in each panel (data not shown). Note that most of the fibers have several bouton-like swellings. $C$, Labeled fibers within a fiber tract. $D-F$, Neuron cell bodies surrounded by labeled bouton-like structures. In the cell shown in $F$, the nucleus appears in outline reflecting the lack of fluorescent structures over this region of the soma. Scale bar: $15 \mu \mathrm{m}$ for $A-C ; ; 10 \mu \mathrm{m}$ for $D-F$.

neurons at ED 11 and ED 18. The level of activity of this enzyme has previously been shown to correspond directly to the innervation status of sympathetic neurons (Mawe et al., 1990). Cryostat sections of an ED 11 lumbar sympathetic chain, processed for histochemical demonstration of $\mathrm{CO}$ activity (enzyme activity is proportional to density of reaction product), revealed that the majority of cells were lightly stained, some barely above background levels (Fig. 4A). An occasional cell at this stage, however, was more darkly stained (Fig. $4 A$, arrowheads). Figure $4 B$ shows a histogram of the OD values from individual neurons in the same tissue.

ED 18 lumbar sympathetic ganglia were processed for $\mathrm{CO}$ activity in parallel with the ED 11 tissue. The enzyme activity of the neurons at ED 18 was considerably greater than at ED 11 (Fig. $4 A$ ), and examination of a histogram of the OD determinations revealed little overlap between the two distributions
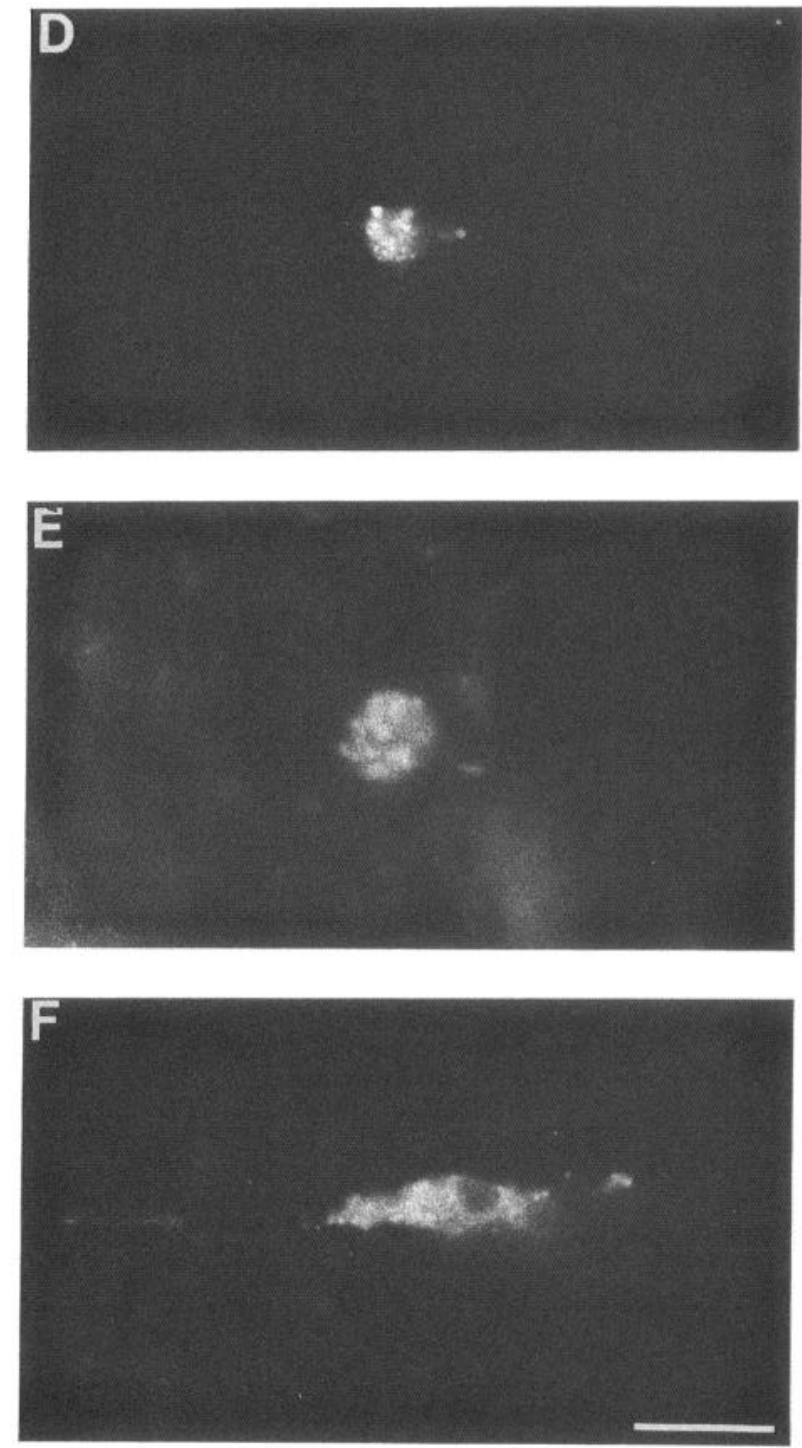

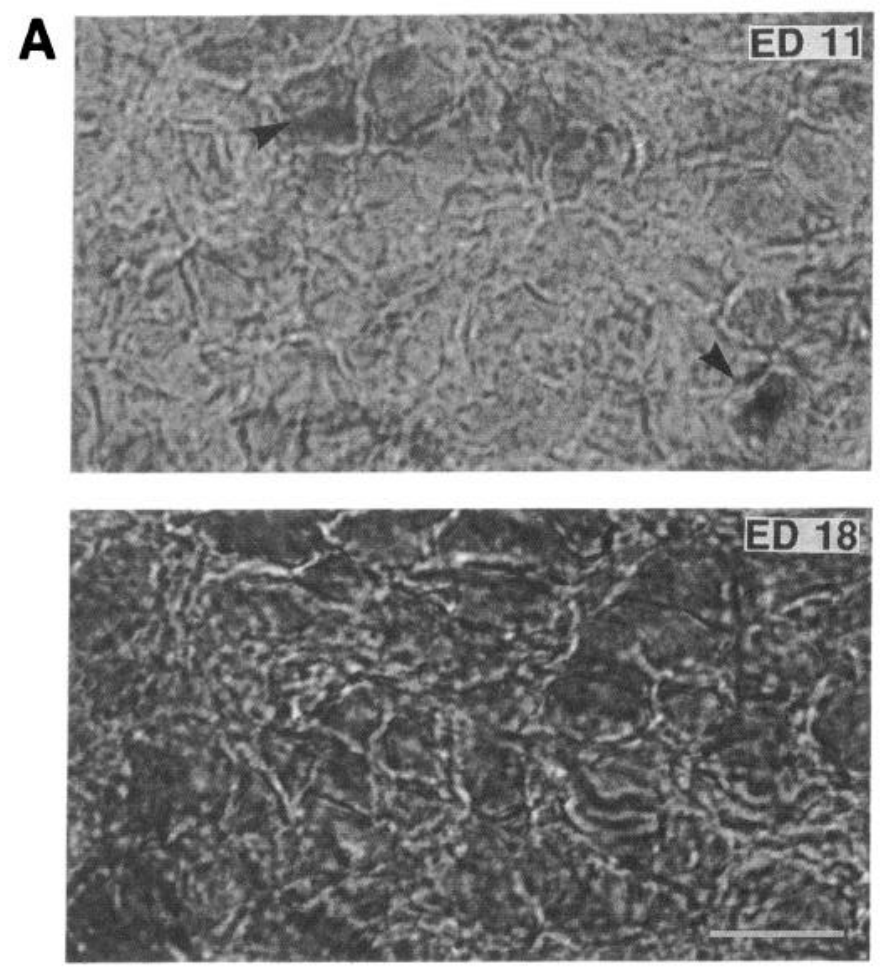

B

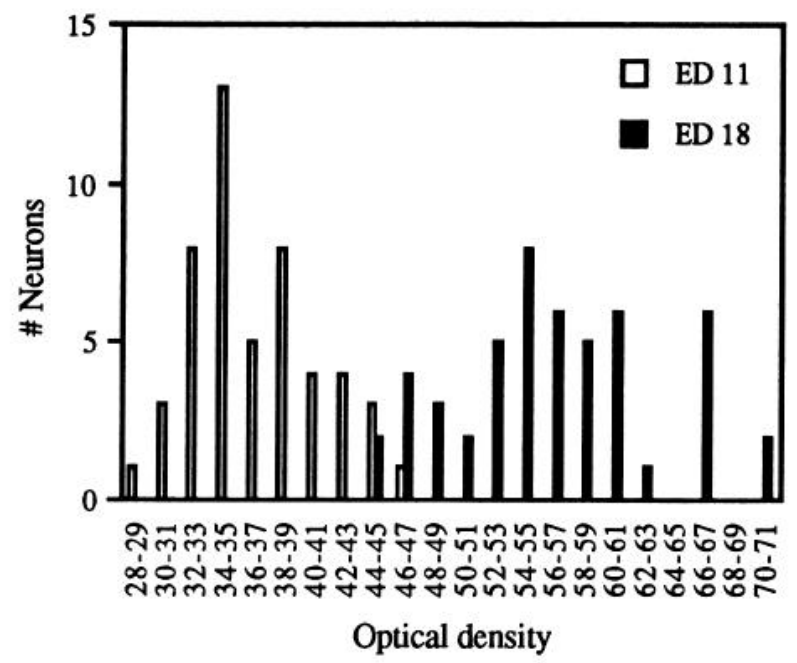

Figure 4. The level of $\mathrm{CO}$ activity, an indicator of electrical activity, increases between ED 11 and ED 18, indicating an increase in synaptic input to sympathetic neurons during this period in vivo. $A$, Cryostat sections from ED 11 and ED 18 lumbar sympathetic chains processed simultaneously for $\mathrm{CO}$ histochemistry. The density of reaction product is proportional to the level of enzyme activity. Arrowheads indicate unusually darkly staining cells observed in ED 11 ganglia. Scale bar, 15 $\mu \mathrm{m}$. $B$, Histogram comparing ED 11 and ED 18 OD values from the tissue shown above. Each value is the mean OD per neuron; cells were randomly selected from all lumbar ganglia (L1-L5). Mean OD increased $\approx 54 \%$ from $37 \pm 2$ at ED 11 to $57 \pm 1$ at ED 18 .

increased 4.4-fold, from $31 \pm 7 \mathrm{pA}(n=22)$ at ED 11 to 137 $\pm 10 \mathrm{pA}(n=22)$ at ED 17 . Twenty-three percent $(5$ of 22$)$ of the ED 11 cells had no detectable ACh response, whereas all ED 17 neurons were positive.
A
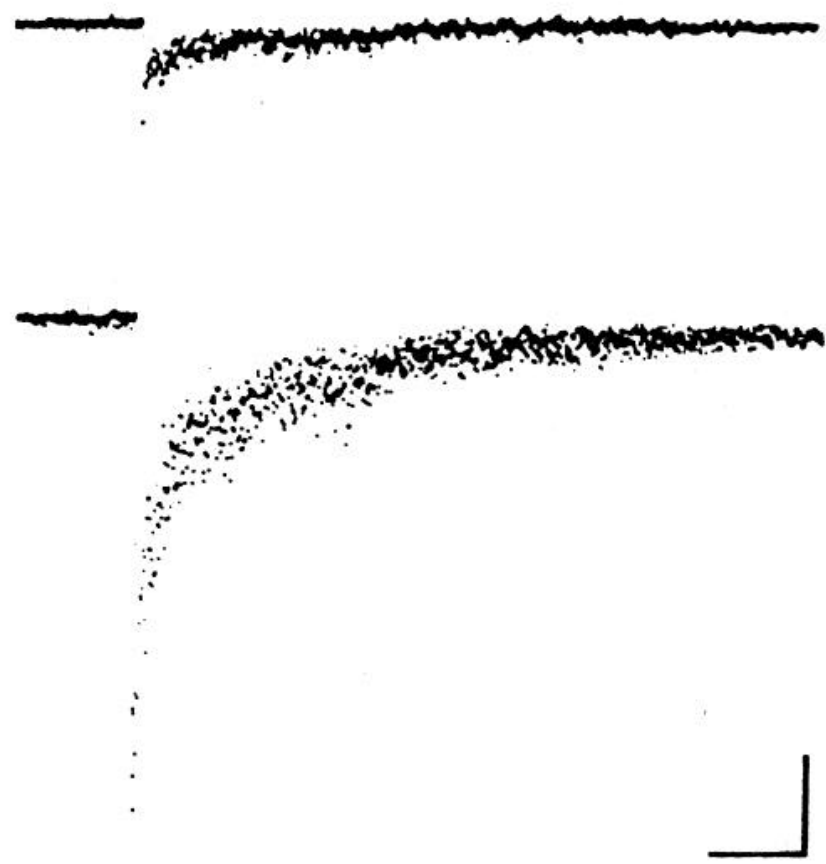

B

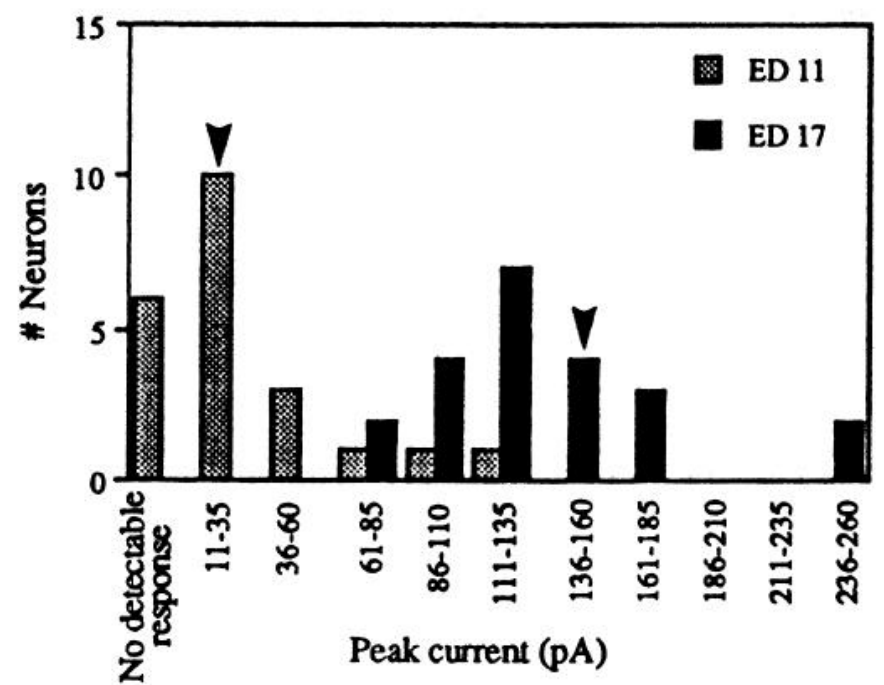

Figure 5. ACh sensitivity of sympathetic neurons increases during innervation in vivo. $A$, Representative $\mathrm{ACh}$-induced macroscopic currents from acutely dispersed ED 11 (top) and ED 17 (bottom) lumbar sympathetic neurons. $\mathrm{ACh}=500 \mu \mathrm{M}$. Membrane potential $=-60 \mathrm{mV}$. Calibration: $25 \mathrm{pA}, 2$ sec. $B$, Histogram displaying all peak ACh-evoked current values obtained for each embryonic age. The mean peak current (arrowheads) increased from $31 \pm 7 \mathrm{pA}( \pm \mathrm{SEM} ; n=22)$ at ED 11 to $137 \pm 10 \mathrm{pA}(n=22)$ at ED 17 . Note that $23 \%(5$ of 22$)$ of the ED 11 cells had no detectable ACh response. 
A

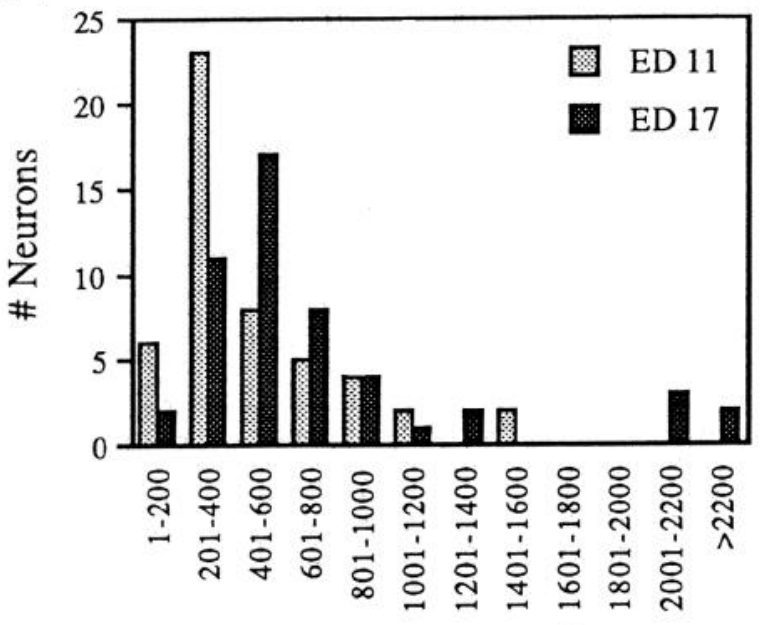

Surface area $\left(\mu \mathrm{m}^{2}\right)$

B

\section{ED 11}

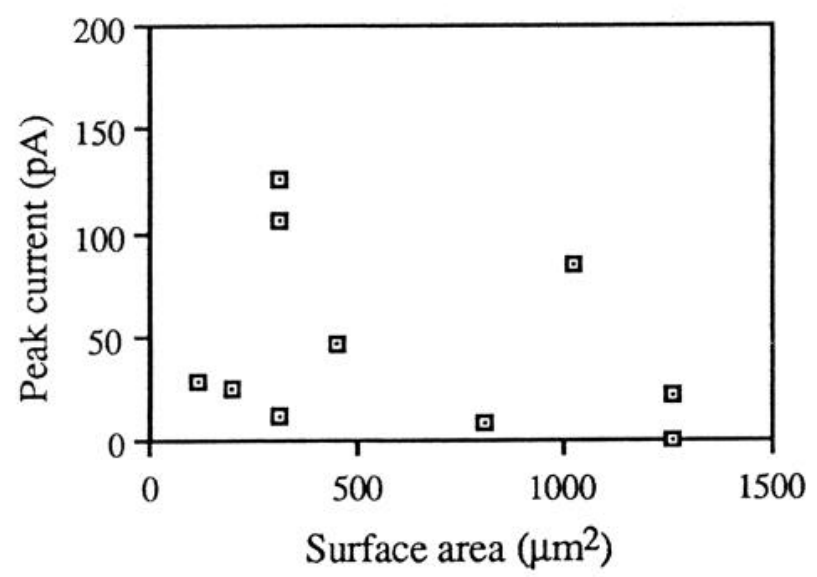

\section{ED 17}

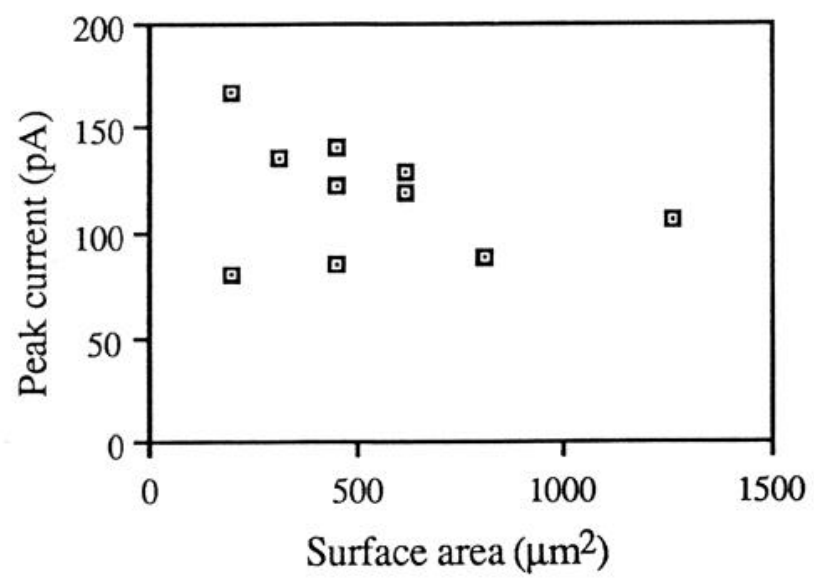

The observed increase in sensitivity is not due to increased cell surface area (with AChR density remaining constant). The mean surface area of ED 11 and ED 17 neurons was calculated from measurements of cell diameter (surface area determined from cell diameter is directly correlated to surface area determined from cell capacitance; see Materials and Methods). Comparison of population histograms of surface area values for ED 11 and ED 17 acutely dispersed neurons revealed a 55\% increase (from $473 \pm 45 \mu \mathrm{m}^{2}$ at ED 11, $n=50$, to $731 \pm 94 \mu \mathrm{m}^{2}$ at ED $17, n=50$; Fig. $6 A$ ) that cannot account for the $\approx 350 \%$ increase in sensitivity. ACh sensitivity also does not correlate with surface area on a cell-by-cell basis at either embryonic age. Plots of peak ACh-evoked current versus surface area for ED 11 and ED 17 neurons reveal no correlation (Fig. $6 B$; ED 11: $r=-0.28$, $n=10$; ED 17: $r=-0.29, n=10$ ).

\section{Biophysical and pharmacological properties of AChRs expressed by neurons from ED 11 animals}

The increased ACh sensitivity of neurons following innervation in vivo might be due to changes in the number and/or biophysical properties of the AChRs. We evaluated a possible contribution of changes in AChR channel properties by comparing $\mathrm{ACh}$ activated single-channel currents in neurons acutely dispersed on ED 11 with currents in neurons removed on ED 17.

Cell-attached patch recordings from neurons acutely dispersed from ED 11 animals revealed three amplitudes of AChactivated channels. Nonconsecutive segments from a cell-attached patch recording illustrate each of the three classes (Fig. $7 A ; 2.5 \mu \mathrm{M}$ ACh; patch membrane potential $=-50 \mathrm{mV}$ relative to rest potential). Figure $7 C$ is an amplitude histogram in which the values of all points in the sampled portion of the record are plotted to provide an unbiased estimate of the single-channel amplitudes. The three peaks indicate three amplitude classes. Superimposed on the histogram is the sum of three Gaussian curves with means \pm SD of $1.9 \pm 0.3 \mathrm{pA}, 3.5 \pm 0.3 \mathrm{pA}$, and $4.5 \pm 0.2 \mathrm{pA}$. We refer to these three classes as $\mathrm{S}, \mathrm{M}$, and $\mathrm{L}$ (for small, medium, and large) since steady-state current-voltage curves in the cell-attached configuration are identical to those of AChRs in ED 10 lumbar sympathetic neurons maintained in vitro (Moss et al., 1989; Table 1). Thus, the multiple subtypes and their characteristic conductances are apparently faithfully retained by neurons in vitro (see Discussion).

More detailed study of the properties of these channels in the inside-out patch-clamp configuration indicates that the three classes differ both in slope conductance and in the extent of rectification at more negative holding potentials (Fig. $7 B$ ). Varying membrane potential from $-50 \mathrm{mV}$ to $-70 \mathrm{mV}$ resulted in ohmic (i.e., linear) changes in current amplitude for each class. Linear regression of data from inside-out patches yielded slope conductance values of $20 \mathrm{pS}, 26 \mathrm{pS}$, and $40 \mathrm{pS}$.

\footnotetext{
Figure 6. ACh sensitivity does not correlate with cell size. A, Observed increase in ACh sensitivity is not due to an increase in cell surface area. Histogram of surface area determinations for both ED 11 and ED 17 acutely dispersed lumbar sympathetic neurons. Surface area was calculated from cell diameter. Compared to the observed $\approx 350 \%$ increase in peak ACh-evoked current, the mean surface area increased only $55 \%$, from $473 \pm 45 \mu \mathrm{m}^{2}(n=50)$ at ED 11 to $731 \pm 94 \mu \mathrm{m}^{2}(n=50)$ at ED 17. B, ACh sensitivity does not correlate with cell surface area at either embryonic age: peak $\mathrm{ACh}$-induced current plotted versus cell surface area for both ED 11 and ED 17 acutely dispersed sympathetic neurons. ED 11: $r=-0.28, n=10$; ED 17: $r=-0.29, n=10$.
} 
A

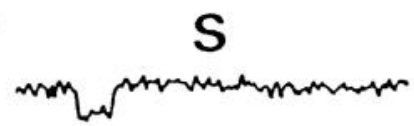

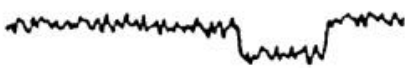

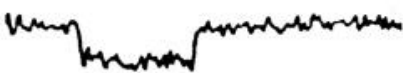

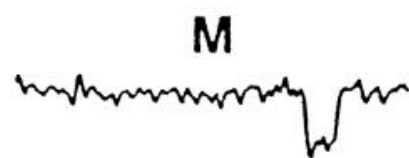

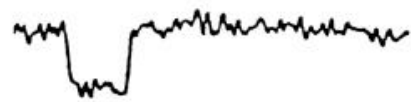

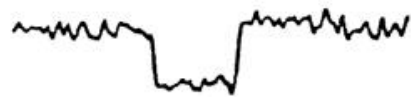

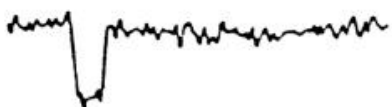

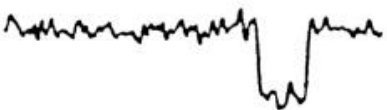

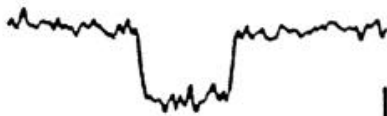

B

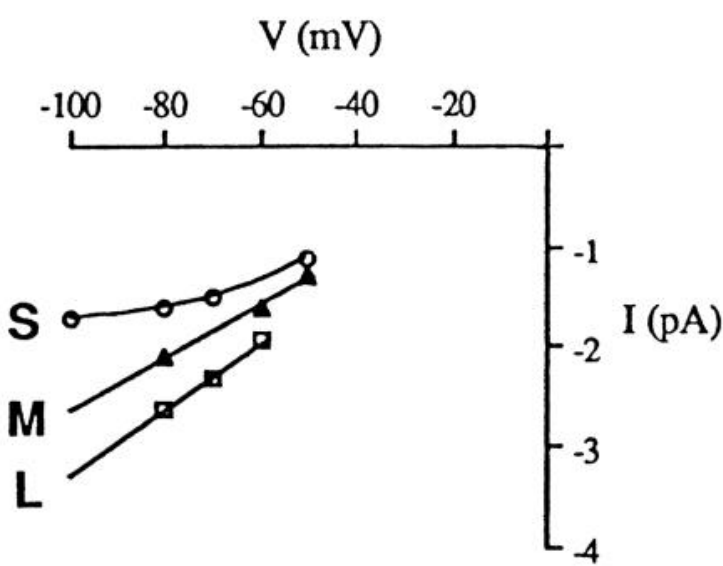

C

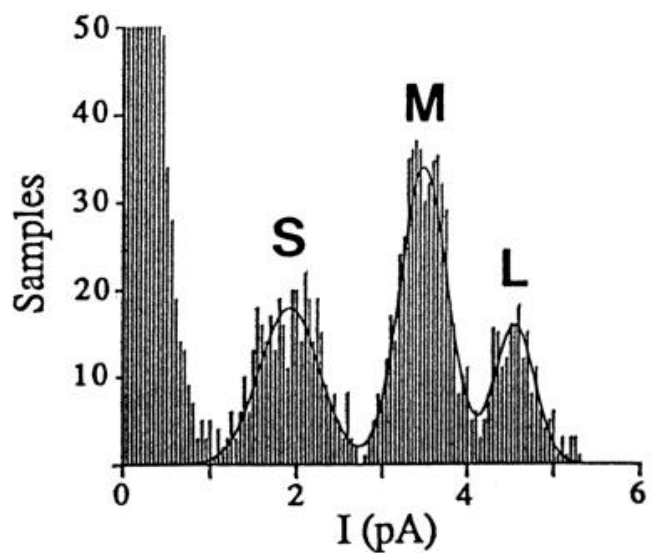

Figure 7. ACh activates three distinct channel amplitude classes in acutely dispersed ED 11 neurons. $A$, Nonconsecutive traces of a cell-attached patch recording from an acutely dispersed ED 11 neuron showing the $\mathrm{S}, \mathrm{M}$, and $\mathrm{L}$ channel classes. The traces were digitally low-pass filtered at $1.5 \mathrm{kHz}$. ACh concentration $=2.5 \mu \mathrm{M}$. Patch potential $=-50 \mathrm{mV}$ relative to rest potential. Calibration: $7.5 \mathrm{pA}, 5 \mathrm{msec}$. $B$, Single-channel current amplitude versus membrane potential. These data were obtained in the inside-out patch-clamp configuration; each current-voltage curve was obtained from a separate patch. In this example, the S, M, and L classes had slope conductances of $20 \mathrm{pS}, 26 \mathrm{pS}$, and $40 \mathrm{pS}$, respectively. The S class rectifies significantly at hyperpolarized potentials; the conductance between $-50 \mathrm{mV}$ and $-70 \mathrm{mV}$ is $20 \mathrm{pS}$, whereas between $-50 \mathrm{mV}$ and $-100 \mathrm{mV}$, the conductance is only $12 \mathrm{pS}$. $C$, Amplitude histogram showing that the three classes give rise to three peaks in the distribution. Superimposed on the histogram is the sum of three Gaussian curves with means \pm SD of $1.9 \pm 0.3 \mathrm{pA}, 3.5 \pm 0.3 \mathrm{pA}$, and $4.5 \pm 0.2 \mathrm{pA}$.

Table 1. Comparison of AChR channel properties in acutely dispersed neurons versus neurons maintained in vitro

Conductance (pS)

Acutely dispersed
neurons

\begin{tabular}{|c|c|c|c|c|c|c|c|c|}
\hline \multirow[b]{2}{*}{ Class } & & & & \\
\hline & ED 11 & ED 17 & ED 10 & ED 17 & ED 11 & ED 17 & ED 11 & ED 17 \\
\hline$S$ & $17 \pm 1$ & $22 \pm 1$ & $14 \pm 1$ & $23 \pm 1$ & $100 \%$ & $80 \%$ & $63 \%$ & $30 \%$ \\
\hline M & $28 \pm 2$ & $35 \pm 1$ & $27 \pm 1$ & $38 \pm 2$ & $27 \%$ & $27 \%$ & $83 \%$ & $57 \%$ \\
\hline $\mathrm{L}$ & $46 \pm 3$ & $47 \pm 1$ & $49 \pm 2$ & $50 \pm 1$ & $23 \%$ & $57 \%$ & $50 \%$ & $67 \%$ \\
\hline XL & NP & $72 \pm 2$ & NP & $69 \pm 6$ & NP & $3 \%$ & NP & $8 \%$ \\
\hline
\end{tabular}

AChR conductance and frequency of occurrence of each channel class were determined for both acutely dispersed neurons and neurons from animals of the same developmental stage but then maintained in vitro for 6-8 d prior to recording. Conductance values from acutely dispersed neurons were either determined from cell-attached patch recordings at 30 , 50 , and $70 \mathrm{mV}$ applied potential or calculated from channel amplitude determinations at $50 \mathrm{mV}$, assuming a cellular rest potential of $-50 \mathrm{mV}$, with identical results. NP, Not present.

${ }^{a}$ Data from Moss et al. (1989). 
Recordings from inside-out patches at more hyperpolarized potentials revealed considerable rectification of the $\mathrm{S}$ class (i.e., the current-voltage relationship is nonlinear). The conductance of the $\mathrm{S}$ class over the linear range of the curve (between -50 $\mathrm{mV}$ and $-70 \mathrm{mV}$ ) is approximately $20 \mathrm{pS}$, whereas between $-50 \mathrm{mV}$ and $-100 \mathrm{mV}$ the conductance is $\approx 12 \mathrm{pS}$. The current-voltage relationship for both the $\mathrm{M}$ and $\mathrm{L}$ channel classes remains ohmic over this range (data not shown).

The $\mathrm{S}, \mathrm{M}$, and $\mathrm{L}$ channel classes also differ in their relative contribution to overall channel activity. The frequency of occurrence of each class, determined from 30 "active" cell-attached patches (i.e., patches containing channel activity, 3 min recordings, $2.5 \mu \mathrm{M} \mathrm{ACh}$, patch potential $-50 \mathrm{mV}$ relative to rest) revealed that $\mathrm{S}$ is the most common class, occurring in $100 \%$ of the patches. The $\mathrm{M}$ and $\mathrm{L}$ classes contributed about equally to overall channel activity, occurring in $27 \%$ and $23 \%$ of patches, respectively. Note that this analysis reveals the relative frequency of appearance of the classes, rather than differences in the frequency of channel opening; opening frequencies of the three classes are quite similar (median opening frequency for each class $\approx 0.03$ openings/sec; $2.5 \mu \mathrm{M} \mathrm{ACh}$ ).

\section{The $S, M$, and $L$ classes differ in sensitivity to NBT}

ED 11 neurons, whether examined just following dispersal or after being maintained 1 week in vitro, express the same three AChR amplitude classes. Since the S, M, and L classes are observed in isolation (Moss et al., 1989), the three classes represent distinct AChR subtypes. To probe possible structural differences between the subtypes, we examined their relative sensitivity to NBT, an antagonist specific for some neuronal nicotinic AChRs (Ravdin and Berg, 1979; Chiappinelli, 1983; Loring et al., 1984).

To test whether each channel class is sensitive to NBT, we examined channel block by $100 \mathrm{~nm}$ NBT, a concentration that effectively blocks NBT-sensitive AChRs in other cultured neurons (Sah et al., 1987). To determine the control level of channel activity, cell-attached patches were first scored for the presence of each channel class. After a $45 \mathrm{~min}$ incubation in toxin, a second set of patches was scored in the same manner. Figure $8 \mathrm{~A}$ shows the combined results of two experiments (a total of 10 control patches, 10 experimental patches) showing that all classes were substantially inhibited. The $\mathrm{S}$ class decreased to $33 \%$ of the control level of activity, and the $\mathrm{M}$ and L conductance classes were both completely blocked. It should be noted that these experiments were performed on lumbar sympathetic neurons maintained in vitro. Thus, the control levels of channel activity for each class differ from that in acutely dispersed neurons. Inhibition of AChR channel activity by NBT was only partially reversible. After a $60 \mathrm{~min}$ incubation in toxin-free media, S, M, and L channel activity increased significantly but not to control levels (data not shown). This partial recovery over $1 \mathrm{hr}$ is consistent with previous studies of recovery of AChactivated currents following NBT treatment in other neurons (Lipton et al., 1987; Sah et al., 1987).

To test for differences in NBT sensitivity between S-, M-, and L-type channels, we examined the effects of lower concentrations of toxin (15 nM and $25 \mathrm{~nm}$ ). Figure $8 B$ shows the combined results of five experiments (a total of 23 control patches, 23 experimental patches) indicating that the $\mathrm{AChR}$ subtypes may be distinguished by their differential sensitivity to NBT. The S class is the least sensitive to toxin block, decreasing only slightly to $93 \%$ of control. In contrast, the $\mathbf{M}$ class openings were sig-
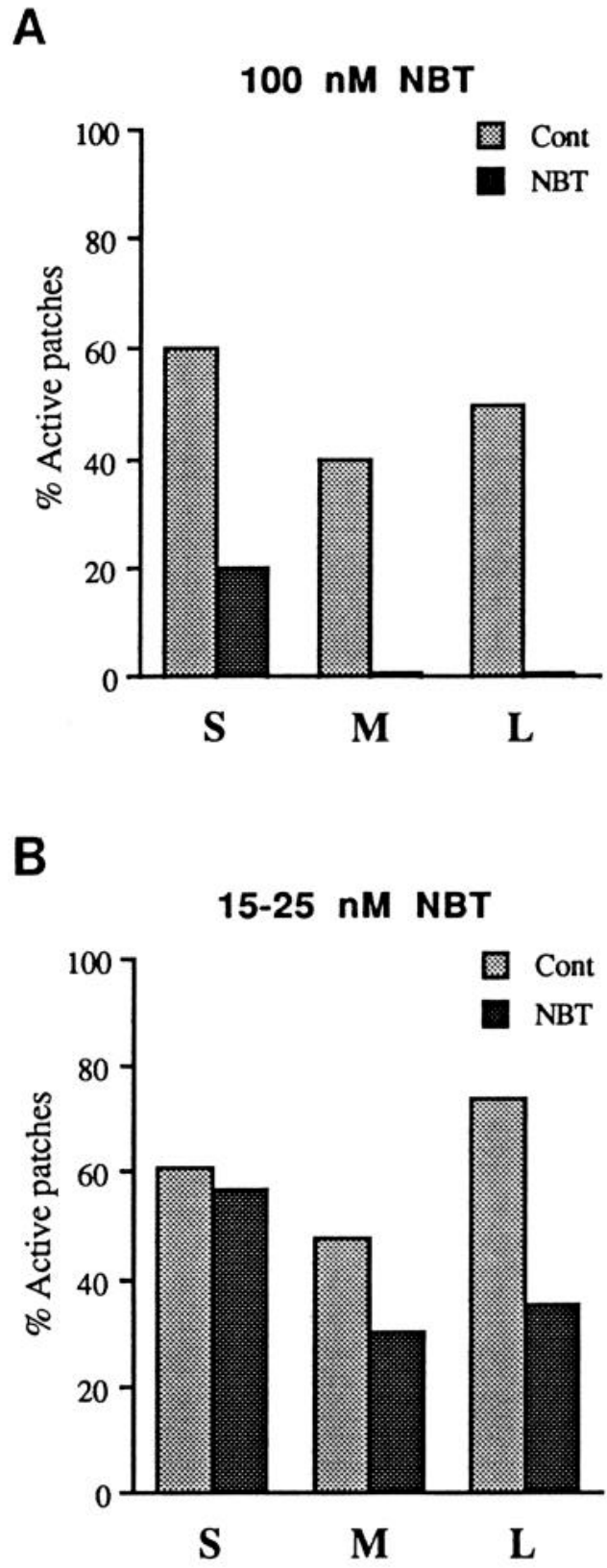

Figure 8. S, M, and $\mathrm{L}$ classes differ in sensitivity to NBT. A, Each channel class is substantially blocked by $100 \mathrm{~nm}$ NBT. The S class decreased to $\approx 33 \%$ of the control level of activity. Both the M and $\mathrm{L}$ classes were completely blocked (two experiments, 10 patches per condition). $B$, Block by 15-25 nM NBT revealed that the $\mathrm{S}, \mathrm{M}$, and $\mathrm{L}$ classes differ in sensitivity to NBT. The S class is the least sensitive to toxin block, decreasing only slightly to $\approx 93 \%$ of control. In contrast, the M channel was significantly inhibited by toxin, decreasing to $\approx 63 \%$ of control. The L class is the most sensitive to NBT, decreasing to $\approx 47 \%$ of control (five experiments, 23 patches per condition). It should be noted that these experiments were performed on lumbar sympathetic neurons maintained in vitro. Thus, the control levels of channel activity for each class differ from that in acutely dispersed neurons.

nificantly inhibited by NBT, decreasing to $64 \%$ of control. Finally, the L channel class is the most sensitive to the toxin, with channel activity reduced to $47 \%$ of control. Analysis of opening frequency data for each class under these conditions confirms the differential sensitivity of the subtypes to NBT block (data not shown). 
A
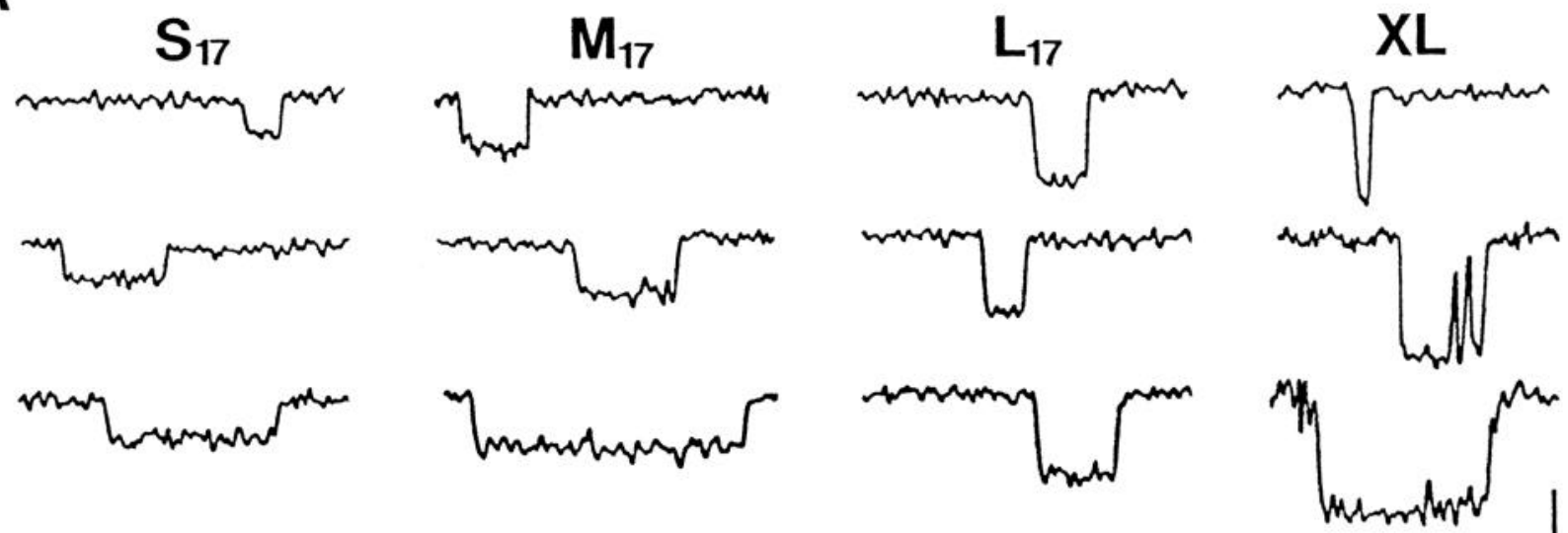

B
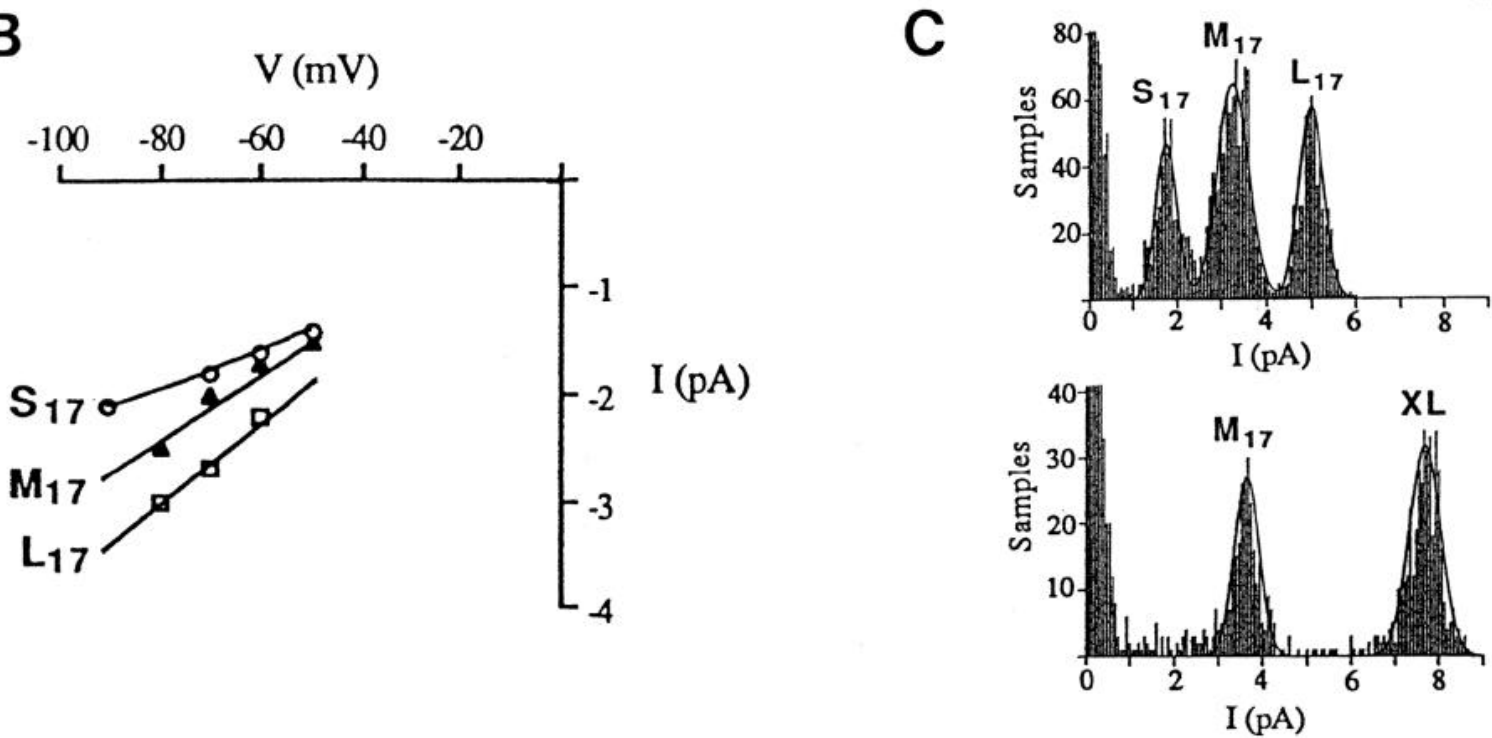

Figure 9. AChR channel properties change in a manner consistent with the observed increase in ACh sensitivity. A, A fourth, larger ACh-activated amplitude class, denoted XL, is present: nonconsecutive traces from four cell-attached patch recordings from an acutely dispersed ED 17 neuron illustrating the $\mathrm{S}_{17}, \mathrm{M}_{17}, \mathrm{~L}_{17}$, and $\mathrm{XL}$ channel classes. The traces were digitally low-pass filtered at $1.5 \mathrm{kHz}$. ACh concentration $=2.5 \mu \mathrm{M}$. Patch potential $=-50 \mathrm{mV}$ relative to rest potential. Calibration: $7.5 \mathrm{pA}, 5 \mathrm{msec}$. $B$, The slope conductances of both the $\mathrm{S}$ and $\mathrm{M}$ (but not $\mathrm{L}$ ) classes increase by $\approx 30-40 \%$, with the shift in the $S$ class possibly due to a decrease in the extent of rectification. Single-channel current amplitude is plotted against membrane potential. The current-voltage curve for $\mathrm{S}_{17}$ was obtained from a separate patch. $C$, Amplitude histograms from two different cell-attached patches showing that the XL class gives rise to a distinct peak in the amplitude distribution. The top histogram shows the $\mathrm{S}_{17}, \mathrm{M}_{17}$, and $\mathrm{L}_{17}$ channel classes; superimposed on the histogram is the sum of three Gaussians with means $( \pm \mathrm{SD})$ of $1.9 \pm 0.2 \mathrm{pA}, 3.4 \pm 0.3 \mathrm{pA}$, and $5.0 \pm 0.2 \mathrm{pA}$. The bottom histogram shows the $\mathrm{M}_{17}$ and XL classes; superimposed on the histogram is the sum of two Gaussian curves with means $( \pm \mathrm{SD})$ of $3.7 \pm 0.3 \mathrm{pA}$ and $7.6 \pm 0.4 \mathrm{pA}$.

\section{AChRs undergo developmental changes in channel properties consistent with an increase in ACh sensitivity}

Cell-attached patch recordings from acutely dispersed ED 17 neurons revealed a fourth, larger-amplitude ACh-activated channel class (denoted XL). Nonconsecutive segments from cellattached patch recordings illustrate all four channel classes, now denoted $\mathbf{S}_{17}, \mathbf{M}_{17}, \mathbf{L}_{17}$, and XL, seen at this embryonic age (Fig. $9 A ; \mathrm{ACh}=2.5 \mu \mathrm{M}$; patch potential $=-50 \mathrm{mV}$ relative to rest potential). Figure $9 C$ includes two amplitude histograms from two different cell-attached patches showing that the XL class gives rise to a distinct peak in the amplitude distribution. The bottom histogram shows the $\mathrm{M}_{17}$ and XL classes; superimposed on the histogram is the sum of two Gaussian curves with means
$( \pm \mathrm{SD})$ of $3.7 \pm 0.3 \mathrm{pA}$ and $7.6 \pm 0.4 \mathrm{pA}$. The top histogram shows the $\mathrm{S}_{17}, \mathrm{M}_{17}$, and $\mathrm{L}_{17}$ channel classes; superimposed on the histogram is the sum of three Gaussians with means $( \pm \mathrm{SD})$ of $1.9 \pm 0.2 \mathrm{pA}, 3.4 \pm 0.3 \mathrm{pA}$, and $5.0 \pm 0.2 \mathrm{pA}$. The low frequency of occurrence of $X L$ channel openings $(\approx 3 \%$ of cellattached patches) prohibited determination of slope conductance; however, its amplitude at a membrane potential of -100 $\mathrm{mV}$ (membrane potential $=-50 \mathrm{mV}$ below an assumed rest potential of $-50 \mathrm{mV}$ ) indicates a conductance of $\approx 72 \mathrm{pS}$, consistent with results obtained in ED 17 neurons maintained in vitro (Moss et al., 1989; Table 1). Some patches from neurons dispersed on ED 17 contained only XL openings, indicating that $\mathrm{XL}$ represents a new $\mathrm{AChR}$ subtype, rather than the simultaneous opening of smaller conductance channels. 
A second change in channel properties is an increase in the conductances of the $\mathrm{S}$ and $\mathrm{M}$ channel classes (compare Figs. $7 B$, $9 B$ ). The conductance of $S_{17}$ is $\approx 42 \%$ larger than that of the $S$ class at ED 11, if one estimates the conductances over the range of maximal rectification $(-50$ to $-100 \mathrm{mV}$; from $\approx 12 \mathrm{pS}$ at ED 11 to $\approx 17 \mathrm{pS}$ at ED 17 ). When conductance is estimated in the voltage range where the current-voltage relationship is ohmic (between $-50 \mathrm{mV}$ and $-70 \mathrm{mV}$ ), the $\mathrm{S}$ class conductance is $\approx 20 \mathrm{pS}$ at both embryonic ages. Thus, the increased conductance of the $\mathrm{S}$ class following innervation in vivo may reflect a decrease in the extent of rectification. The slope conductance of the M class increases by nearly $30 \%$ (from $\approx 26 \mathrm{pS}$ at ED 11 to $\approx 33 \mathrm{pS}$ at ED 17), and is ohmic over the voltage range examined at both stages (between $-50 \mathrm{mV}$ and $-100 \mathrm{mV}$; data not shown). There is no change in the slope conductance of the L class $(\approx 40 \mathrm{pS}$ at both ED 11 and ED 17). The demonstration of conductance shifts of the $\mathrm{S}$ and $\mathrm{M}$ class in excised patches indicates a change in the channels themselves rather than a more general change in cellular ionic composition. Similar shifts in $\mathrm{S}$ and $\mathrm{M}$ channel conductance are seen in cell-attached patch recordings from ED 10 and ED 17 neurons maintained in vitro (see Discussion, Table 1).

Finally, there is a also a shift in the relative contribution of the $\mathrm{S}$ and $\mathrm{L}$ classes to overall channel activity in neurons acutely dispersed before and after innervation in vivo. Scoring of 30 active patches revealed that the percentage of patches with $\mathrm{S}$ type openings decreased somewhat (from $100 \%$ to $\approx 80 \%$ of the patches at ED 11 and ED 17, respectively) whereas the contribution of the L channel class increased approximately 2.5 -fold (from $23 \%$ at ED 11 to $57 \%$ at ED 17). There was no detectable change in the contribution of the $\mathrm{M}$ channel class.

\section{AChR channels cluster during innervation in vivo}

In addition to regulation of AChR functional properties, further studies revealed significant changes in the distribution of surface AChRs during early stages of innervation in vivo. Analysis of channel opening frequency (number of openings/sec, all three channel classes combined) revealed that $\approx 96 \%$ of the patches on ED 11 neurons had low levels of channel activity (mean opening frequency $=0.04 \pm 0.01$ openings $/ \mathrm{sec}$ ). In contrast, patches on ED 17 neurons fell into two distinct classes: low activity and high activity (Fig. 10A). Sixty percent of the patches had low levels of channel activity (mean opening frequency = $0.07 \pm 0.01$ openings/sec), whereas the average level of channel activity in the remaining $40 \%$ of the patches was $\approx 30$-fold higher (mean opening frequency $=2.10 \pm 0.20$ openings $/ \mathrm{sec}$ ). One possible explanation for these results is that there are two populations of ED 17 neurons, one with low ACh sensitivity and another with high ACh sensitivity. However, this is inconsistent with measurements of $\mathrm{ACh}$-induced peak currents that indicate only one population of ED 17 neurons (Fig. $5 B$ ). These data suggest that AChRs on ED 17 neurons may be clustered; that is, individual neurons may have focal areas of membrane with a high receptor density or "hot spots."

To examine AChR channel clustering more directly, we mapped the distribution of surface AChRs on both ED 11 and ED 17 neurons by obtaining three to five cell-attached patches per cell. For the majority of ED 11 neurons in which we detected significant AChR channel activity $(70 \%$ of the neurons had few or no detectable AChRs; see below), all patches had low levels of channel activity (data not shown). In contrast, we detected both low- and high-activity patches on 40\% (8 of 20) of ED 17
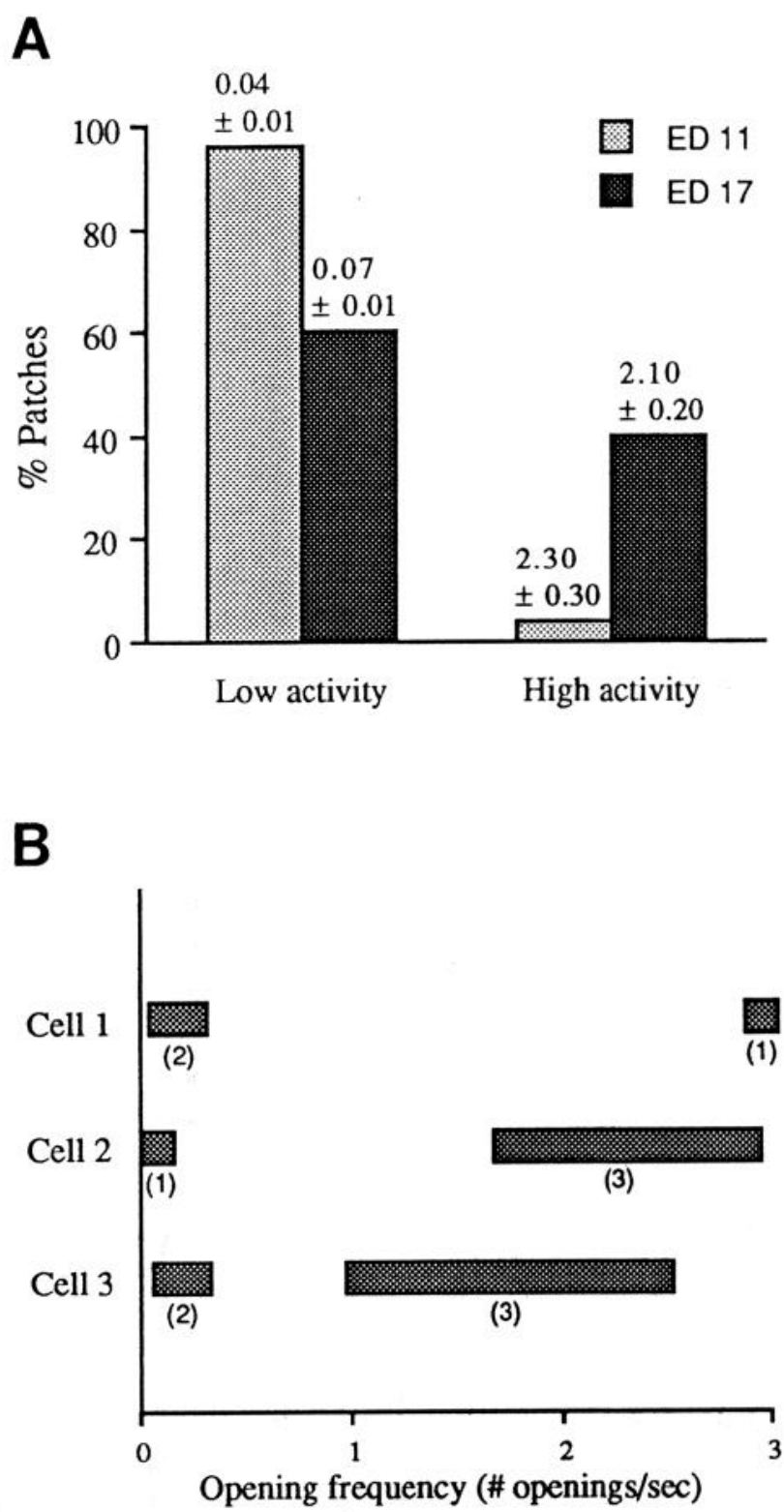

Figure 10. AChRs become clustered during innervation in vivo. $A$, In ED 11 neurons, $\approx 96 \%$ (51 of 53 ) of the patches had very low levels of channel activity; (mean opening frequency $=0.04 \pm 0.01$ openings/ sec). In contrast, patches in ED 17 neurons fell into two distinct classes: low activity and high activity [60\% (30 of 50) and $40 \%(20$ of 50$)$ of the patches, respectively]. Opening frequencies of low-activity patches ranged from 0.00 to 0.30 openings/sec, with a mean of $0.07 \pm 0.01$ openings/sec. Opening frequencies of high-activity patches ranged from 0.70 to 4.50 openings/sec, with a mean of $2.10 \pm 0.20$ openings/sec. $B$, To determine whether AChRs are clustered in ED 17 neurons, we mapped the distribution of surface AChRs by obtaining three to five patches per cell. This figure shows representative mapping results from three neurons. Horizontal bars indicate the ranges of opening frequency for low- and high-activity patches. Numbers in parentheses indicate the number of patches falling within each range.

neurons; Figure $10 \mathrm{~B}$ shows representative mapping results from three such cells. If the channels were randomly distributed on ED 17 neurons, measurements of channel opening frequency would be normally distributed and the mean of the observed values $(0.7$ openings/sec) would have an SD of about 0.2 , with $\approx 67 \%$ of the values within $1 \mathrm{SD}$ of the mean. However, the lack of random distribution of the channels is evident from the 
A

\section{ED 11}

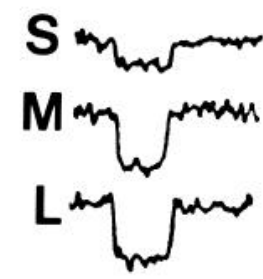

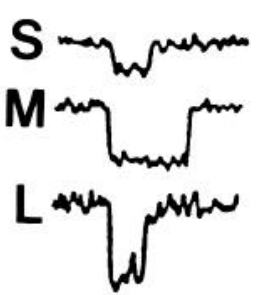

B
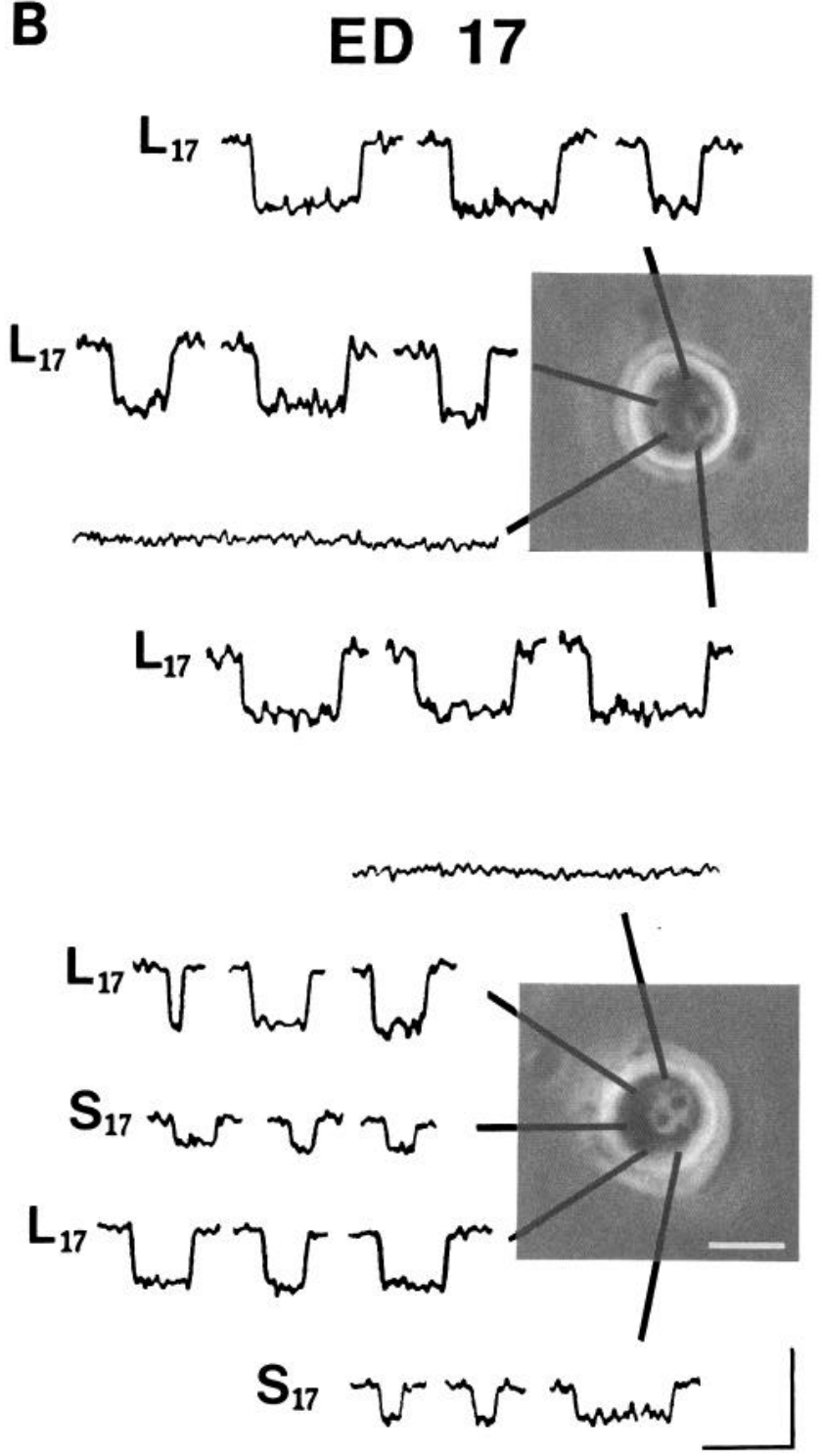

fact that the SD is 1.2 , with only $25 \%$ of the measured values within one SD of the mean.

These results suggest that at ED 11, when there is apparently little preganglionic input to lumbar sympathetic ganglia, $\mathrm{AChRs}$ are, for the most part, evenly distributed over the soma. However, by ED 17, following a dramatic increase in the number of preganglionic fibers entering the ganglia, $\mathrm{AChRs}$ are distributed in clusters or "hot spots."

AChR subtypes become segregated during innervation in vivo

A population study of neurons removed at ED 10 and ED 17 and maintained in vitro revealed that at ED 17 there were more patches with just one class of AChR channels (Moss et al., 1989). This increase in the number of single-class patches might reflect an increase in the number of neurons expressing only a single AChR class. Alternatively, it may be due to a change in the distribution of AChRs such that AChR subtypes are segregated into homogeneous domains on the cell surface. To distinguish these possibilities, we mapped the distribution of surface AChR subtypes on acutely dispersed ED 11 and ED 17 neurons.

Mapping ED 11 neurons revealed three patterns of $\mathrm{AChR}$ channel subtype distribution. Seventy percent (14 of 20) of the neurons had no or few detectable AChR channels: $25 \%$ of these cells had no detectable AChRs (no openings were observed during the first $3 \mathrm{~min}$ in any of the three to five patch recordings per cell), and in the remaining $45 \%$ of the neurons, AChR channels were very rare and only of the $S$ type. In $30 \%$ of the neurons at ED 11, however, significant AChR channel activity was detected over the entire cell surface. The majority of these patches contained multiple AChR subtypes (Fig. 11A).

Mapping of acutely dispersed neurons from ED 17 animals revealed a substantially different pattern of $\mathrm{AChR}$ distribution. Twenty-five percent ( 5 of 20 ) of the neurons resembled the last subset of ED 11 neurons; that is, most patches on the same neuron had AChRs that were a mix of channel subtypes. The majority of neurons (75\%) mapped at this stage, however, expressed AChRs that were segregated by subtype. Channel subtype segregation was often manifested on a cell-by-cell basis; that is, in 7 of 20 cells, all of the patches on the cell were exclusively $\mathrm{S}_{17}$ or $\mathrm{M}_{17}$ or $\mathrm{L}_{17}$ (Fig. $11 B$, top). Less commonly (2 of 20 cells), we found two types of AChR channels spatially segregated from one another on the same neuron. For example, on the neuron illustrated in Figure $11 B$ (bottom), we obtained two patches with just $S_{17}$ channels and two patches with just $L_{17}$ channels. The remaining neurons (6 of 20 ) showed partial spatial segregation. That is, we observed patches containing just one

Figure 11. AChR subtypes become segregated during innervation in vivo. Representative mapping results illustrating the distribution of surface AChRs in ED 11 and ED 17 neurons. Sample openings illustrate all amplitudes observed in a $3 \mathrm{~min}$ recording from each patch. Patches were obtained from the indicated regions of each soma. $A$, Mapping results from an ED 11 neuron in which all three AChR subtypes were detected. $B$, Mapping results from two ED 17 neurons illustrating the two types of segregation observed. Top, In 35\% of ED 17 neurons examined, only one AChR subtype was detected. In the neuron shown here, only $\mathrm{L}_{17}$ openings were observed in all patches. Bottom, We occasionally found ED 17 neurons in which two $A C h R$ subtypes were completely segregated. In the neuron shown here, both $\mathrm{S}_{17}$ and $\mathrm{L}_{17}$ were observed, but never in the same patch. Traces were low-pass filtered at $2 \mathrm{kHz}$. ACh concentration $=2.5 \mu \mathrm{M}$. Patch potential $=-50 \mathrm{mV}$ relative to rest potential. Calibration: $7.5 \mathrm{pA}, 5 \mathrm{msec}$. Scale bar, $10 \mu \mathrm{m}$. 
subtype as well as patches containing multiple subtypes on the same neuron (data not shown).

If these patterns of $\mathrm{AChR}$ channel distribution were binomially distributed, one would expect to detect spatial segregation (partial or complete) in $70 \%$ of the neurons and segregation on a cell-by-cell basis in only $15 \%$ of the neurons (based on overall probability of obtaining a single-class patch $=0.5$ ). However, we observed these two phenotypes in approximately $40 \%$ and $35 \%$ of the neurons, respectively. $\chi^{2}$ analysis (Zar, 1984) of this comparison of expected versus observed $\mathrm{AChR}$ distribution, based on binomial parameters, indicates that there is $<0.1 \%$ probability of the observed result occurring by chance. These results indicate two levels of segregation of AChR subtypes: spatial segregation on individual neurons as well as segregation on a neuron-by-neuron basis.

\section{Discussion}

To determine the role of cellular interactions in the development of transmitter sensitivity, we must first ascertain the profile of changes in receptor properties relative to the timing of synapse formation. The principle findings of this study are that ACh sensitivity, AChR channel function, and AChR distribution are modified concurrent with a significant increase in presynaptic input to lumbar sympathetic neurons of the embryonic chick. Comparison of the AChR properties of acutely dispcrsed ncurons to those of neurons maintained in vitro suggests that most features of $A C h R$ channels are conserved despite their removal from presynaptic and other in vivo influences. Finally, spatial segregation of the channel subtypes following innervation indicates a highly precise regulation of $A C h R$ distribution in these neurons.

\section{Innervation of embryonic chicken sympathetic neurons in vivo}

The establishment of presynaptic input from the preganglionic neurons to embryonic chicken lumbar sympathetic ganglia was examined by orthograde DiI labeling in combination with $\mathrm{CO}$ histochemistry. Apparently, most of the neurons are not innervated by ED 11 since there are relatively few DiI-labeled fibers and the level of $\mathrm{CO}$ staining is low in ganglia at this stage. In contrast, there is a dramatic increase in the number of labeled preganglionic fibers and synaptic bouton-like structures as well as in the level of CO staining in ED 17 ganglia, consistent with more widespread synaptic input.

The level of $\mathrm{CO}$ activity reflects both the presence and the extent of synaptic input (Mawe et al., 1990). That is, enzyme activity increases in a graded fashion as the level of synaptically driven responses increases from none to low- to high-frequency, suprathreshold activity. The rare, darkly stained ED 11 neurons most likely represent cells with some innervation early on. In contrast, $>90 \%$ of the neurons at ED 17 have $\mathrm{CO}$ activity higher than that of any of the cells at ED 11, suggesting that both the number and the extent of synaptic input are greatly increased over this time of development in vivo.

Preliminary studies with both retrograde labeling of preganglionic neurons and immunocytochemical staining of the ganglia for synaptic vesicle antigen and ChAT also suggest a significant increase in the extent of synaptic input between ED 11 and ED 17 (Devay et al., 1991; P. Devay and L. Role, unpublished observations). Electron microscopic studies also indicate that synapses are rare in sympathetic ganglia at ED 9-10 (Hruschak et al., 1982; Ross et al., 1990).

\section{Increased $A C h$ sensitivity during innervation in vivo}

Our observation that $\mathrm{ACh}$ sensitivity of embryonic chicken sympathetic neurons increases significantly concurrent with innervation in vivo is consistent with previous findings in peripheral systems of frog and chick in vivo and in vitro (in vivo: Margiotta and Gurantz, 1989; Engisch and Fischbach, 1990; L. M. Marshall, personal communication; in vitro: Role 1988; Gardette et al., 1991). Innervation of chick ciliary ganglia is corrclated with an increase in the level of $\alpha 3$ subunit mRNA (Boyd et al., 1988) and immunocytochemical labeling of surface AChRs (Jacob, 1991). In fact, a recent study of binding of an anti-AChR monoclonal antibody in chick ciliary ganglia did not detect any surface AChRs prior to innervation in vivo (Jacob, 1991). Likewise in the CNS, the upregulation of $\mathrm{AChR} \beta 2$ (non- $\alpha$ ) subunit RNA in chick optic tectum is temporally related to and dependent upon innervation of the tectum (Matter et al., 1990). Regulation of transmitter sensitivity with innervation may not be limited to cholinergic synapses: responses to glutamate (O'Brien and Fischbach, 1986) and norepinephrine (Pun et al., 1985) are also enhanced when specific populations of central neurons are cocultured with appropriate presynaptic sources.

Innervation per se is not required for increased $\mathrm{ACh}$ sensitivity in neurons, however. Soluble factors from cholinergic neurons are equally as effective as presynaptic input (Gardette ct al., 1991), and ACh sensitivity can increase in (cholinergic) ciliary ganglion neurons that have never received synaptic input (Engisch and Fischbach, 1992). In the present study, the ACh sensitivity of neurons prior to innervation was extremely low. However, there was some detectable ACh-evoked current in $\approx 80 \%$ of the neurons at this stage (ED 11), suggesting that sympathetic neurons may express AChRs prior to contact by presynaptic neurons. Since cholinergic neuron-derived soluble factor(s) enhances the rate of appearance of new AChRs on uninnervated sympathetic neurons (Gardette et al., 1991), even neurons that had not received presynaptic input in vivo may have been exposed to soluble factor(s) that upregulates the number of surface AChRs.

Several studies have examined the role of presynaptic input in the regulation of neuronal $\mathrm{ACh}$ sensitivity by testing the effects of denervation. Ablation of presynaptic input after synapses have been established has little, if any, effect on $\mathrm{ACh}$ sensitivity in both sympathetic and parasympathetic neurons (Dunn and Marshall, 1985; Jacob and Berg, 1988; McEachern et al., 1989: in contrast to results suggested from earlier work; see Schuetze and Role, 1987, for review). Consistent with this observation, preganglionic denervation of chick ciliary ganglia results in only a small decrease in the level of $\alpha 3$ subunit mRNA (Boyd et al., 1988).

Considering the results of these denervation experiments along with those from experiments examining the regulation of neuronal AChRs with de novo interactions between pre- and postsynaptic neurons suggests that the establishment but not the maintenance of $\mathrm{ACh}$ sensitivity may be regulated by presynaptic input. This is in contrast to muscle, where denervation causes a dramatic activity-dependent increase in AChR number (reviewed in Schuetze and Role, 1987; Brehm and Henderson, 1988).

\section{Changes in AChR channel properties with synaptogenesis}

Examination of ACh-gated channels in acutely dispersed neurons removed prior to or following innervation in vivo indicates 
that presynaptic input may be an important determinant of AChR channel properties and distribution. However, presynaptic influences may be less important in maintaining $\mathrm{AChR}$ channel properties and distribution (see below).

We detect multiple AChR subtypes in lumbar sympathetic neurons studied immediately following dispersal from ED 11 ganglia. Comparison of the AChR channels in these neurons to those from ncurons dispersed at the same developmental stage but then maintained in vitro for $\approx 1$ week reveals an identical array of steady-state slope conductances (Table 1). This observation suggests that the profile of AChR subtypes at ED 11 may be "imprinted" or stably expressed, independently of presynaptic input or other in vivo influences.

We found that the AChR subtypes also differ in sensitivity to NBT, with the $S$ class being the least sensitive and the L class the most sensitive to toxin block. Xenopus oocyte expression experiments have shown that the particular combination of $\alpha$ and $\beta$-subunits confers toxin sensitivity. This is not surprising since it has been shown that for the muscle $\mathrm{AChR}$, although the $\alpha$-subunit contains the agonist and $\alpha$-bungarotoxin binding sites, the neighboring subunit influences the affinity for agonist and antagonist binding (Blount and Merlie, 1989; Pederson and Cohen, 1990). Thus, for neuronal AChRs, while the $\alpha 3 \beta 2$ combination is NBT sensitive (Boulter et al., 1987), $\alpha 2 \beta 2$ (Luetje et al., 1990) and $\alpha 3 \beta 4$ (Duvoisin et al., 1989; but see Papke and Heinemann, 1991) may be resistant to toxin block. These results, and studies deleting individual subunits (Listerud et al., 1991), suggest that the AChR subtypes in lumbar sympathetic neurons may have different subunit compositions (see Role, 1992).

Finally, examination of AChR channels in inside-out patches from acutely dispersed ED 11 neurons revealed rectification of the $\mathrm{S}$ channel class at hyperpolarized potentials. This might be an intrinsic property of this subtype of $\mathrm{AChR}$ or voltage-dependent block by magnesium, which produces inward rectification of AChRs in PC12 cells (Ifune and Steinbach, 1990; Mathie et al., 1990).

Examination of neurons acutely dispersed from animals following the arrival of presynaptic input reveals several changes in the properties of $\mathrm{AChR}$ channcls. The acquisition of a new subtype (XL) as well as the increased conductances of the $S$ and $M$ classes are apparently features of the AChRs that are expressed concurrent with innervation, but are retained even if the neurons are cultured in the absence of input for a week or more (Table 1). Although the overall developmental shift to a greater number of large conductance events is seen in both acutely dispersed and cultured neurons, the relative abundance of the three channel classes differs between the two preparations at each embryonic age. Thus, although there is a decrease in the contribution of the $\mathrm{S}$ class and an increase in the contribution of the L class with prolonged maintenance of the cells in vitro (as during normal development), the contribution of the $\mathrm{M}$ class increases steadily. This suggests that the regulated expression of the $\mathrm{M}$ class may require an (unidentified) in vivo influence. Likewise, the contribution of the $S$ class is lower at both stages in neurons in vitro, suggesting that the maintained expression of this subtype may require other factors. Alternatively, these results may indicate that some aspects of neuronal AChR channel expression may change with time in vitro as has been described for AChRs in Xenopus myocytes (Brehm et al, 1984; Leonard et al., 1984) and voltage-gated channels in Xenopus spinal neurons (O'Dowd et al., 1988).
Changes in distribution of surface AChRs during innervation in vivo

Whereas the majority $(96 \%)$ of patches on neurons removed before innervation in vivo have extremely low AChR channel activity, we find both low- and high-activity patches on individual neurons following innervation. These data are consistent with the formation of receptor clusters in embryonic chicken sympathetic neurons during innervation in vivo. An alternative interpretation is that the channels in the high-activity patches simply have a greater opening rate constant. However, there is ample precedent for innervation-dependent clustcring of $A C h R s$ at the neuromuscular junction where a focal increase in AChR density at the synaptic site is one of the earlier events in synaptogenesis (reviewed in Salpeter and Loring, 1986; Schuetze and Role, 1987; Laufer et al., 1989). Likewise, examination of the distribution of surface AChRs in autonomic ganglia using anti-AChR monoclonal antibodies and ${ }^{125}$ I-NBT has demonstrated that neuronal AChRs are clearly clustered at synapses (Marshall, 1981; Jacob et al., 1984; Loring and Zigmond, 1987; Sargent and Pang, 1989; Jacob, 1991).

Mapping the distribution of AChR channel subtypes before and after the arrival of presynaptic input in vivo suggests innervation-dependent changes in the spatial organization of the subtypes. Initially, the neurons may express few, if any, AChRs. This is consistent with results in chick ciliary ganglion examining surface anti-AChR immunolabeling early in embryogenesis (Jacob, 1991). The $\mathrm{S}$ channel class may be the first AChR subtype expressed, followed by M- and L-type channels. This temporal pattern of expression is tentatively proposed from our finding ED 11 neurons that contained either no detectable AChRs, a very low level of $S$ channel activity, or low levels of activity of all three channel classes.

Neurons removed from ED 17 animals (following the arrival of presynaptic input) often expressed only one AChR subtype. In the majority of neurons that expressed more than one subtype, the different AChR classes were either partially or completely spatially segregated from one another. A few neurons resembled those at earlier stages, having mixed patches of two or more AChR subtypes.

Segregation of other types of ACh binding sites from one another has also been reported. Studies of the distribution of $\alpha$ bungarotoxin ( $\alpha$-BGT) versus NBT binding sites on ciliary ganglion neurons reveals that the $\alpha$-BGT sites are excluded from sites of presynaptic apposition, whereas NBT sites are not (Jacob and Berg, 1983; Loring et al., 1985). The functional role of $\alpha$ BGT sites is unclear, however, since although an $\alpha$-BGT binding subunit $(\alpha 7)$ forms functional homooligomeric channels in Xenopus oocytes and many classes of neurons express $\alpha 7$ (Couturier et al., 1990; Listerud et al., 1991), $\alpha$-BGT typically does not block channel activation (but see Listerud et al., 1991).

Segregation of functional AChR channels has also been suggested previously. AChRs expressed by B and C cells in frog sympathetic ganglia are kinetically distinct, with an approximately twofold difference in apparent mean open time (Marshall, 1986). The gating kinetics of the channels can be regulated by their presynaptic input; denervated $B$ cells, when reinnervated by $\mathrm{C}$ fibers, express AChRs characteristic of C cells (Marshall, 1985). Furthermore, when neurons are innervated by both types of presynaptic input (i.e., both B and C fibers to a single neuron), the postsynaptic responses evoked suggest that B-and 
C-type AChR channels are restricted to the sites of their respective presynaptic inputs (Marshall, 1989).

\section{Functional consequences of changes in AChR channel properties, clustering, and segregation during innervation in vivo}

Several changes in the nature of synaptic transmission in vitro (Gardette et al., 1991; Hume and Honig, 1991) may result from the changes in AChRs described here. First, the amplitudes of spontaneous (unit) excitatory postsynaptic currents (EPSCs) increase with synaptic development, consistent with a greater contribution of higher-conductance channels and enhanced postsynaptic ACh sensitivity (Gardette et al., 1991). Second, the amplitude histograms of the EPSCs have two or three peaks. Although this may be due to presynaptic mechanisms, the multiple EPSC peaks might result from activation of AChR clusters of different subtypcs (i.c., an S-only patch would be expected to produce an EPSC of about half the amplitude of an L-only patch). Further support for this idea comes from studies of Hume and Honig (1991). In approximately $50 \%$ of the innervated neurons they examined, the distribution of spontaneous EPSP amplitudes also contained discrete peaks; however, the peaks were not integral multiples of the smallest EPSP. Furthermore, the frequency of larger-amplitude events was sometimes larger than that for smaller-amplitude events. Honig and Hume (1991) suggest that the EPSP peaks correspond to release of individual quanta at synapses with different AChR subtypes. Thus, the segregation of AChR subtypes may encode differences in the efficacy of synaptic transmission for distinct inputs on the same neuron.

\section{References}

Blount P, Merlie JP (1989) Molecular basis of the two nonequivalent ligand binding sites of the muscle nicotinic acetylcholine receptor. Neuron 3:349-357.

Boulter J, Connolly J, Deneris E, Goldman D, Heinemann S, Patrick J (1987) Functional expression of two neuronal nicotinic acetylcholine receptors from cDNA clones identifies a gene family. Proc Natl Acad Sci USA 84:7763-7767.

Brehm P, Henderson L (1988) Regulation of acetylcholine receptor channel function during development of skeletal muscle. Dev Biol 129:1-11.

Brehm P, Kidokoro Y, Moody-Corbett F (1984) Acetylcholine receptor properties during development of Xenopus muscle cells in culture. J Physiol (Lond) 357:203-217.

Boyd RT, Jacob MH, Couturier S, Ballivet M, Berg DK (1988) Expression and regulation of neuronal acetylcholine receptor mRNA in chick ciliary ganglia. Neuron 1:495-502.

Chiappinelli VA (1983) $\kappa$-Bungarotoxin: a probe for the neuronal nicotinic receptor in the avian ciliary ganglion. Brain Res 277:9-21.

Choi DW, Fischbach GD (1981) GABA-mediated synaptic potentials in chick spinal cord and sensory neurons. J Ncurophysiol 45:605620.

Couturier S, Bertrand D, Matter J-M, Hernandez M-C, Bertrand S, Millar N, Valera S, Barkas T, Ballivet M (1990) A neuronal nicotinic acetylcholine receptor subunit $(\alpha 7)$ is developmentally regulated and forms a homo-oligomeric channel blocked by $\alpha$-BTX. Neuron 5:847856.

Daubas P, Devillers-Thiery A, Geoffroy B, Martinez S, Bessis A, Changeux JP (1990) Differential expression of the neuronal acetylcholine receptor $\alpha 2$ subunit gene during chick brain development. Neuron 5: 49-60.

Devay P, Listerud MD, Role LW (1991) Synapse formation in chick lumbar sympathetic ganglia in vivo: timing of presynaptic input and projections to target. Soc Neurosci Abstr 17:251.

Dryer S, Chiappinelli VA (1985) An intracellular study of synaptic transmission and dendrite morphology in sympathetic neurons of the chick embryo. Dev Brain Res 22:99-111.
Dunn PM, Marshall LM (1985) Lack of nicotinic supersensitivity in frog sympathetic neurons following denervation. J Physiol (Lond) 363:211-225.

Duvoisin RM, Deneris ES, Patrick J, Heinemann S (1989) The functional diversity of the neuronal nicotinic acetylcholine receptors in increased by a novel subunit: $\beta 4$. Neuron $3: 487-496$.

Engisch KL, Fischbach GD (1990) The development of ACh- and GABA-activated currents in normal and target-deprived embryonic chick ciliary ganglia. Dev Biol 139:417-426.

Engisch KL, Fishbach GD (1992) The development of ACh- and GABA-activated currents in embryonic chick ciliary ganglion neurons in the absence of innervation in vivo. J Neurosci 12:1115-1125.

Gardette R, Listerud MD, Brussaard AB, Role LW (1991) Developmental changes in transmitter sensitivity and synaptic transmission in embryonic chicken sympathetic neurons innervated in vitro. Dev Biol 147:83-95.

Hamill OP, Marty A, Neher E, Sakmann B, Sigworth FJ (1981) Improved patch-clamp techniques for high-resolution current recording from cells and cell-free membrane patches. Pfluegers Arch 391:85100.

Hruschak KA, Friedrich VL, Giacobini E (1982) Synaptogenesis in chick paravertebral sympathetic ganglia: a morphometric analysis. Dev Brain Res 4:229-240.

Hume RI, Honig MG (1991) Physiological properties of newly formed synapses between sympathetic preganglionic neurons and sympathetic ganglion neurons. J Neurobiol 22:249-262.

Ifune CK, Steinbach JH (1990) Rectification of acetylcholine-elicited currents in PC12 pheochromocytoma cells. Proc Natl Acad Sci USA $87: 4794-4798$

Jacob MH (1991) Acetylcholine receptor expression in developing chick ciliary ganglion neurons. J Neurosci 11:1701-1712.

Jacob MH, Berg DK (1983) The ultrastructural localization of $\alpha$ bungarotoxin binding sites in relation to synapses on chicken ciliary ganglion neurons. J Neurosci 3:260-271.

Jacob MH, Berg DK (1988) The distribution of acetylcholine receptors in chick ciliary ganglion neurons following disruption of ganglionic connections. J Neurosci 8:3838-3849.

Jacob MH, Berg DK, Lindstrom JM (1984) Shared antigenic determinant between the Electrophorus acetylcholine receptor and a synaptic component on chicken ciliary ganglion neurons. Proc Natl Acad Sci USA 81:3223-3227.

Kuffler SW, Dennis MJ, Harris AJ (1971) The development of chemosensitivity in extrasynaptic areas of the neuronal surface after denervation of parasympathetic ganglion cells in the heart of the frog. Proc R Soc Lond [Biol] 177:555-563.

Laufer R, Fontaine B, Klarsfeld A, Cartaud J, Changeux JP (1989) Regulation of acetylcholine receptor biosynthesis during motor endplate morphogenesis. News Physiol Sci 4:5-9.

Leonard RJ, Nakajima S, Nakajima Y, Takahashi T (1984) Differential development of two classes of acetylcholine receptors in Xenopus muscle in culture. Science 226:55-57.

Levi-Montalcini $\mathrm{R}$ (1950) The origin and development of the visceral system in the spinal cord of the chick embryo. J Morphol 86:253277.

Lipton SA, Aizenman E, Loring RH (1987) Neural nicotinic acetylcholine responses in solitary mammalian retinal ganglion cells. Pfluegers Arch 410:37-43.

Listerud M, Brussaard AB, Devay P, Colman DR, Role LW (1991) Functional contribution of neuronal AChR subunits revealed by antisense oligonucleotides. Science 54:1518-1521.

Loring RH, Zigmond RE (1987) Ultrastructural distribution of ${ }^{125}$ Itoxin $F$ binding sites on chick ciliary neurons: synaptic localization of a toxin that blocks ganglionic nicotinic receptors. J Neurosci 7 : 2153-2162.

Loring RH, Chiappinelli VA, Zigmond RE, Cohen JB (1984) Characterization of a snake venom neurotoxin which blocks nicotinic transmission in the avian ciliary ganglion. Neuroscience 11:989-999.

Loring RH, Dahm LM, Zigmond RE (1985) Localization of $\alpha$-bungarotoxin binding sites in the ciliary ganglion of the embryonic chick: an autoradiographic study at the light and electron microscopic level. Neuroscience 14:645-660.

Luetje CW, Wada K, Rogers S, Abramson SN, Tsuji K, Heinemann S, Patrick J (1990) Neurotoxins distinguish between different neuronal nicotinic acetylcholine receptor subunit combinations. J Neurochem 55:632-640. 
Margiotta JF, Gurantz D (1989) Changes in the number, function, and regulation of nicotinic acetylcholine receptors during neurona development. Dev Biol 135:326-339.

Marshall LM (1981) Synaptic localization of $\alpha$-bungarotoxin binding which blocks nicotinic transmission at frog sympathetic neurons. Proc Natl Acad Sci USA 78:1948-1952.

Marshall LM (1985) Presynaptic control of synaptic channel kinetics in sympathetic neurons. Nature 317:621-623.

Marshall LM (1986) Different synaptic channel kinetics in sympathetic $B$ and $C$ neurons of the bullfrog. J Neurosci 6:590-593.

Marshall LM (1989) Presynaptic influence on postsynaptic channel kinetics is localized to individual synapses. Soc Neurosci Abstr 15: 301.

Mathie A, Colquhoun D, Cull-Candy SG (1990) Rectification of currents activated by nicotinic acetylcholine receptor in rat sympathetic ganglion neurones. J Physiol (Lond) 427:625-655.

Matter J-M, Matter-Sadzinski L, Ballivet M (1990) Expression of neuronal nicotinic acetylcholine receptor genes in the developing chick visual system. EMBO J 9:1021-1026.

Mawe GM, Gardette R, D'Agostaro L, Role L (1990) Development of synaptic transmission at autonomic synapses in vitro revealed by cytochrome oxidase histochemistry. J Neurobiol 21:578-591.

McEachern AE, Jacob MH, Berg DK (1989) Differential effects of nerve transection on the $\mathrm{ACh}$ and GABA receptors of chick ciliary ganglion neurons. J Neurosci 9:3899-3907.

Moss BL, Schuetze SM, Role LW (1989) Functional properties and developmental regulation of nicotinic acetylcholine receptors on embryonic chicken sympathetic neurons. Neuron 3:597-607.

O'Brien RJ, Fischbach GD (1986) Excitatory synaptic transmission between interneurons and motoneurons in chick spinal cord cell cultures. J Neurosci 6:3284-3289.

O'Dowd DK, Ribera AB, Spitzer NC. (1988) Development of voltagedependent calcium, sodium, and potassium currents in Xenopus spinal neurons. J Neurosci 8:792-805.

Papke RB, Heinemann SF (1991) The role of the $\beta 4$-subunit in determining the kinetic properties of rat neuronal nicotinic acetylcholine $\alpha 3$-receptors. J Physiol (Lond) 440:95-112.

Pederson SE, Cohen JB (1990) $d$-Tubocurarine binding sites are located at the $\alpha-\gamma$ and $\alpha-\delta$ subunit interfaces of the nicotinic acetylcholine receptor. Proc Natl Acad Sci USA 87:2785-2789.
Pun RYK, Marshall KC, Hendelman WJ, Guthrie PB, Nelson PG (1985) Noradrenergic responses of spinal neurons in locus coeruleus-spinal cord co-cultures. J Neurosci 5:181-191.

Ravdin PM, Berg DK (1979) Inhibition of neuronal acetylcholine sensitivity by $\alpha$-toxins from Bungarus multicinctus venom. Proc Natl Acad Sci USA 76:2072-2076.

Role LW (1984) Substance P modulation of acetylcholine-induced currents in embryonic chicken sympathetic and ciliary ganglion neurons in vitro. Proc Natl Acad Sci USA 81:2924-2928.

Role LW (1988) Neural regulation of acetylcholine sensitivity in embryonic sympathetic neurons. Proc Natl Acad Sci USA 85:28252829.

Role LW (1992) Diversity in primary structure and function of neuronal nicotinic ACh receptor channels. Curr Opin Neurobiol 2:254262.

Ross S, Fischer A, Unsicker K (1990) Differentiation of embryonic chick sympathetic neurons in vivo: ultrastructure, and quantitative determinations of catecholamines and somatostatin. Cell Tissue Res 260:147-159.

Sah DW, Loring RH, Zigmond RE (1987) Long-term blockade by toxin $\mathrm{F}$ of nicotinic synaptic potentials in cultured sympathetic neurons. Neuroscience 20:867-874.

Salpeter MM, Loring RH (1986) Nicotinic acetylcholine receptor in vertebrate muscle: properties, distribution and neural control. Prog Neurobiol 25:297-325.

Sargent PB, Pang DZ (1988) Denervation alters the size, number, and distribution of clusters of acetylcholine receptor-like molecules on frog cardiac ganglion neurons. Neuron 1:877-886.

Sargent PB, Pang DZ (1989) Acetylcholine receptor-like molecules are found in both synaptic and extrasynaptic clusters on the surface of neurons in the frog cardiac ganglion. J Neurosci 9:1063-1072.

Schuetze SM, Role LW (1987) Developmental regulation of nicotinic acetylcholine receptors. Annu Rev Neurosci 10:403-457.

Yip J (1986) Specific innervation of neurons in the paravertebral sympathetic ganglia of the chick. J Neurosci 6:3459-3464.

Yip J (1990) Identification of location and timing of guidance cues in sympathetic preganglionic axons of the chick. J Neurosci 10:24762484

Zar JH (1984) Biostatistical analysis. Englewood Cliffs, NJ: PrenticeHall. 